Portland State University

PDXScholar

1976

\title{
The utilization of preventive health care services by low income members of a comprehensive prepaid health plan : the impact of outreach services
}

Linda Elmlund Mahoney

Portland State University

Follow this and additional works at: https://pdxscholar.library.pdx.edu/open_access_etds

Part of the Medicine and Health Commons, Social Welfare Commons, and the Social Work Commons Let us know how access to this document benefits you.

\section{Recommended Citation}

Mahoney, Linda Elmlund, "The utilization of preventive health care services by low income members of a comprehensive prepaid health plan : the impact of outreach services" (1976). Dissertations and Theses. Paper 1778.

https://doi.org/10.15760/etd.1777

This Thesis is brought to you for free and open access. It has been accepted for inclusion in Dissertations and Theses by an authorized administrator of PDXScholar. Please contact us if we can make this document more accessible: pdxscholar@pdx.edu. 
THE UTILIZATION OF PREVENTIVE HEALTH CARE SERVICES BY LOW INCOME MEMBERS OF A COMPREHENSIVE PREPAID HEALTH PLAN: THE IMPACT OF OUTREACH SERVICES

$$
\text { by }
$$

Linda Elmlund Mahoney

A practicum submitted in partial fulfillment of the requirements for the degree of

MASTER OF SOCIAL WORK

Portland State University 1976 


\section{APPROVED:}

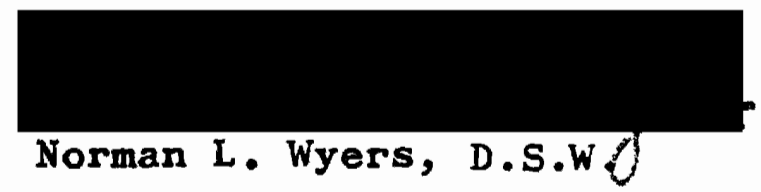




\section{ACKNOWLEDGMENTS}

I would like to thank Donald K. Freeborn, Ph.D., Associate Director, Health Services Research Center-Kaiser Foundation Hospitals, and Vicky Burnham, Research Assistant, Health Services Research Center-Kaiser Foundation Hospitals, for their invaluable assistance in the completion of this project. 
TABLE OF CONTENTS

PAGE

ACKNOWLEDGMENTS •. • • • • • • • • • • • •

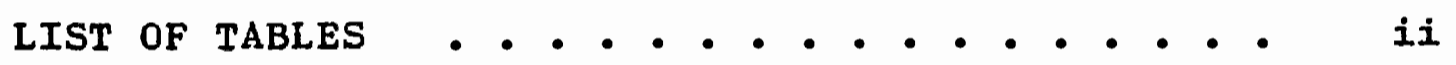

CHAPTER

I INTRODUCTION

II REVIEW OF THE LITERATURE • • • • • •

Preventive Care •. . . . . . 8

Outreach Services •. . . . - 20

III DESCRIPTION OF THE STUDY POPULATION

AND RESEARCH OBJECTIVES • • • • • • 35

IV FINDINGS AND DISCUSSION • • • • • • 53

V SUMMARY AND CONCLUSIONS . . . . . 63

BIBLIOGRAPHY •. • • • • • • • • • • 69

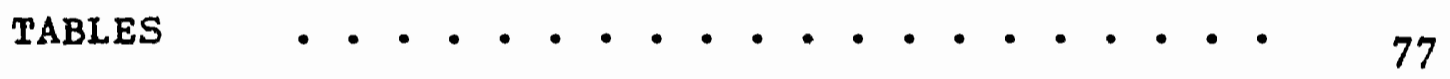




\section{LIST OF TABLES}

TABLE

PAGE

1 Rate Per Hundred Person/Years of Distribution of Primary Immunizations for Total Health Plan Sample and Neighborhood Health Center Population, 1972.

2 Rate Per Hundred Person/Years of Distribution of Preventive Physical Examinations for Males in Total Health Plan Sample and Neighborhood Health Center Population, 1972.

3 Rate Per Hundred Person/Years of Distribution of Preventive Physical Examinations for Females in Total Health Plan Sample and Neighborhood Health Center Population, 1972.

4 Rate Per Hundred Person/Years of Distribution of Pap Smears for Total Health Plan Sample and Neighborhood Health Center Population, 1972 . 


\section{CHAPTER I}

\section{INTRODUCTION}

A reading of recent studies in preventive health care behavior recalls the proverb about the blind men and the elephant: each man is able to describe the part of the animal he is closest to, but none can see, and so none can put their diverse and often contradictory opinions together to come up with an accurate description of the whole elephant. Similarly, in preventive health care studies, each researcher or research group is able to observe the preventive health care utilization patterns of specific populations at particular times, but the conclusions reached are often based on less than complete knowledge. This is especially true of the research into what makes low income people use preventive services in certain ways.

The reasons that the research conclusions are often of limited value are many. Preventive care is offered in a variety of health care settings, and is paid for through a variety of financing mechanisms. Individuals can obtain, for example, a yearly physical examination from their regular physicians, and receive a bill. This is traditional 
in "fee-for-service" private medical practice. If they need immunizations they may go to a public clinic. or if they belong to a comprehensive prepaid health plan, or have insurance through a health insurance organization, such as Blue Cross, they may receive a number of preventive care services, depending on their group's coverage.

Until recently it has been difficult to draw conclusions about how low income people use health care services because they did not receive them in what has been called the "mainstream" of medical practice, except as "charity" patients in private hospitals. And, in general, this has tended to be for emergency rather than for preventive services. Instead of going to their private physicians to be seen by appointment, they have gone to public clinics, often to experience long waits to see a physician or medical student who does not know them.

Although the use of preventive services by low income people is an area in which considerable research has been conducted, especially in the past ten to fifteen years, the difference in medical settings in which the care is received, and in financing mechanisms that separate the "paying customers" from "charity" cases, makes it difficult to tell whether the poor and nonpoor use these services different1y.

Other reasons that much of the research in the area is less conclusive than it might be is that many studies have 
been limited to small geographical areas, or have been conducted during a short period of time, or have been studies of populations not representative of an area. ${ }^{1}$ As a result, many research issues and questions still need systematic investigation.

This chapter will first discuss the definition of prevention in a general way, and then explain the rationale for the selection of the measures of preventive care used in this study. Second, there are two factors that contribute indirectly to the public's use of these services: one is the historical separation between preventive medicine and traditional medical practice; the other is tha attitudes of physicians themselves towards preventive care.

\section{WHAT IS PREVENTIVE CARE?}

Preventive care services can be defined simply as diagnosis and treatment obtained where disease is not present or suspected. This would include regular physical examinations, such as "well-baby" visits for infants and children and "yearly checkups" for adults. But these describe only one component of preventive services. Another is represented by immunizations, in which the danger of exposure to disease is sufficiently great to justify

${ }^{1}$ Irwin M. Rosenstock, "Prevention of Illness and Maintenance of Health," in Poverty and Health, ed. John Kosa et al. (Cambridge, Mass.: Harvard University Press, 1969, p.195. 
inoculating a particular high-risk population in order to maintain a high level of health in the community. Primary immunizations, as defined in this study, consist of the basic"package" of immunizations given to infants and children to prevent their contracting diphtheria, pertussis, tetanus, poliomyelitis, smallpox, and measles. A third type of preventive service is represented by the Papanicolaou smear, which, like an, immunization, is routinely administered at prescribed intervals (usually six months to one year) to women. This is not a test that prevents an individual woman from contracting cancer of the cervix, but rather detects the disease in a sufficiently early stage so that the cancer does not spread to other parts of the body. These three measures are all "preventive" services, but each represents a slightly different dimension of the concept of prevention.

The research literature includes many other measures. They include toothbrushing, ${ }^{2}$ tuberculosis tests, ${ }^{3}$. family planning, and prenatal care. 4 Even abortion and sterilization could, if one expanded the definition, be seen as steps

${ }^{2}$ Ibid., p. 199.

$3_{\text {Ibid., p. } 198 .}$

${ }^{4} \mathrm{Jay}$ Brightman et al., "Knowledge and Utilization of Health Resources by Public Assistance Recipients: Public Health and Preventive Medical Resources," Amer. J. Public Health XLVIII (February 1958):197. 
taken to preclude unwanted conditions from occurring, and thus as types of preventive care. In short, the definition of prevention is, like the universe, expanding somewhat faster than we would like it to. Fuchs, for example, extends the definition even further:

It is becoming increasingly evident that many health problems are related to individual behavior. In the absence of dramatic breakthroughs in medical science, the greatest potential for improving health is through changes in what people do and do not do to and for themselves. 5

Clearly this has implications for the individual patient or health care consumer and for national policy, but this argument would move the medical profession and medical care industry away from its traditional role of diagnosing, detecting, and curing disease into one in which it increasingly takes a moral stance about patients' behavior. To use a not entirely frivolous example, do we as a nation want the medical profession (or some other group, such as a legislative body) to tell us that we must not eat butter in such large quantities? It is not clear to what degree the medical profession is prepared to assume this role as moral guardians' of patients' behavior or whether the public would accept it.

5 Victor R. Fuchs, "Health Care and the United States Economic System," Milbank Memorial Fund Quarterly 50 (April 1972):229. 
Elsewhere, Fuchs discusses prevention in terms of national priorities. His example is a striking one:

\begin{abstract}
- - homicide is the leading cause of death among young black males; indeed, it continues to be a significant cause of death right up through middle age; thus if you are a 15-year-old black American male, your chances of being a homicide victim sometime before you reach 55 are 30 out of 1000--more than triple the risk of your dying from tuberculosis. 6

While Fuchs's very interesting views may represent how prevention may be defined in the future, at present we are limited to analyzing statistics based on traditional
\end{abstract} measures of preventive care.

\title{
MEDICAL CARE VS. PREVENTIVE CARE
}

What is the relationship between the traditional practice of medicine and preventive medicine? First, it is important to recognize that, historically, medicine and public health have been separate fields. Traditionally, medicine has addressed itself to treating an individual while public health has addressed itself to treating a population. Medicine's interest, to over-simplify a complex issue, has been to treat and to cure disease, public health's, to prevent the occurrence of disease. As a result, what would appear logically to be two closely related specialties within the same profession have been

${ }^{6}$ Victor R. Fuchs, Who Shall Live? Health, Economics, and Social Choice,, (New York: Basic Books, Inc., 1974), p. 42 . 
two separate disciplines focusing on different issues. Freymann rather bluntly accounts for this separation, at least in some specialties, by suggesting that physicians have traditionally regarded preventive services as "beneath" them:

Preventive medicine figured little in graduate education of pediatricians and obstetricians until the late 1960 's. Residency experience in these fields still tends to concentrate on the clinically spectacular; e.g., endocrinologic diseases, overwhelming infections, low-birth weight infants, complicated deliveries, invasive cancers, etc., while the preventive measures offering far greater potential payoffs in health are regarded as necessary but not particularly interesting. The average resident and his teachers are anxious to escape from the well-child and prenatal clinics and get back to the excitement of the ward and operating room.7

Thus, when looking at utilization rates of preventive care services, especially among low income health care users, it is important to bear in mind that physicians' attitudes toward prevention may affect utilization as much as the attitudes of the patients themselves. Chapter II will discuss the research into the use of preventive health services by low income people.

7John G. Freymann, "Medicine's Great Schism: Prevention vs. Cure: an Historical Interpretation," Medical Care 13:525. 
CHAPTER II

\section{REVIEW OF THE LITERATURE: PREVENTIVE CARE}

\section{PREVENTIVE CARE: AN OVERVIEW}

The following is a review of the research into how low-income people use preventive care services. It will demonstrate that this is an area in which they have historically underutilized a number of preventive services in comparison with other Americans.

Recent research has shown that a number of factors affect utilization, and some of them have looked to the characteristics of the poor themselves as a way of understanding this phenomenon. What is it about poor people that causes them to receive less preventive care? Is it "alienation" and "anomie" that makes them fail to obtain immunizations for themselves and their children? ${ }^{1}$ Is it that they feel they get second-class treatment from medical care providers when they are ill, so tend not to seek out medical care when they are well due to fears of experiencing

${ }^{1}$ Philip M. Moody and Robert M. Gray, "Social Class, Social Integration and the Use of Preventive Health Services," in Patients, Physicians and Illness, ed. E. Gartly Jaco (New York: The Free Press, 1972), p. 263. 
the kind of rejection they did when they were $i 11 ?^{2}$ Do they have different attitudes toward their bodies, believing that parts of the body "wear out" in the course of life and that nothing can be done to maintain health? ${ }^{3}$ or do they have a different sense of time that makes them unable to plan for the future? 4 or do they fail to "place a high value on health?" 5 or do they simply lack the money to obtain the services they need? Some researchers have suggested that lack of finances combined with the problems inherent in obtaining services in a highly fragmented health care system may contribute to underutilization. 6 Their view is that making services equally available both to low and middle income health care consumers in a

2Anse1m Strauss, "Medical Ghettos," in Jaco, p. 382 .

3 Daniel Rosenblatt and Edward A. Suchman, "The UnderUtilization of Medical-Care Services by Blue-Collarites," in Blue-Collar World: Studies of the American Worker, ed. Arthur B. Shostak and William Gomberg (Englewood Cliffs, N.J.: Prentice-Hall, 1964), p. 344 .

${ }^{4}$ Irwin M. Rosenstock, "Prevention of Illness and Maintenance of Health," in Poverty and Health, ed. John Kosa et al. (Cambridge, Mass.: Harvard University Press, 1969), p. 188 .

${ }^{5}$ Catherine Kohler Riessman, "The Use of Health Services by the Poor," Social Policy (May-June 1974):42.

${ }^{6}$ Strauss, "Medical Ghettos," in Jaco, p. 383 . 
comprehensive, prepaid system can eliminate these different utilization rates by different income groups. 7

Since the research literature is extensive, this section will review only what appear to be the major articles and the major points of disagreement among researchers.

Much has been learned about how low income people use all types of health care services in recent years, but no matter how conscientious the researchers have been, no research conclusions are value-free, and all reflect to some degree either the conventional wisdom of the period during which they were written, or the biases and convictions of the researchers, or both.

Catherine Riessman, in her thorough and welldocumented study of health care utilization by the poor, suggests that there have been two major explanations of the different ways the poor use medical care, as compared with other Americans.

7 Merwyn R. Greenlick, "Comparing the Use of Medical Care Services by a Medically Indigent and a General Membership Population in a Comprehensive Prepaid Group Practice Program," Medical Care 10 (May-June 1972). p. 41. ${ }^{8}$ Riessman, "The Use of Health Services by the Poor," 
One is psychocultural, embodying the "culture of poverty" thesis originally formulated by Oscar Lewis in 1959, in which poverty is defined as a "way of lifen or culture comprising a body of interrelated social, economic, and psychological traits (including dependence, violence, easy sex, inability to delay gratification) that are transmitted from generation to generation.9

She suggests that the opposite point of view is expressed by researchers who look more closely at economic factors and at the system through which poor people obtain health care services of all kinds. She calls this the "sociostructural view. ${ }^{10}$ In this frame of reference

- - [e]conomic factors that have been shown to greatly influence the utilization of health services include price of services, the presence or absence of health insurance, and family income.11

This means that when low income people have enough money to obtain health care services, and are encouraged to do so by the health professions, they are able to learn to use preventive services at rates that approach those of more affluent people. This view minimizes the influence of low income life styles and attitudes and beliefs about health care on utilization of preventive services.

${ }^{9}$ Ibid.

${ }^{10}$ Ibid.

${ }^{11}$ Ibid. 
II. REVIEW OF MAJOR ARTICLES

The earliest major study after World War II of health care utilization, as it relates to socioeconomic status, was done by Koos in The Health of Regionville. ${ }^{12}$ In this four-year inquiry into attitudes toward health care of the three major social classes (upper, middle, and lower) in a small town in upstate New York in the early $1950^{\prime} \mathrm{s}$, comparing utilization rates by class, Koos found that the lowest socioeconomic class (Class III) individuals did indeed use fewer preventive services than those in Classes I and II. 13 Twenty-six percent of the Class I population (the professional and managerial group) reported that they had had a "preventive health examination," as compared with $19 \%$ of the Class II respondents, and $4 \%$ of Class III respondents. 14

Later, during the Kennedy and Johnson administrations, social and health services programs were enacted in an attempt to eradicate poverty, and the major research articles from this period, in focusing on the differences

12 Earl L. Koos, The Health of Regionville: What the People Thought and Did About It.(New York: Hafner, 1954).

${ }^{13}$ Ibid., p. 113 .

${ }^{14}$ Ibid. Koos, however, notes that these data may be misleading because he found that "the real importance of this distribution lay in the fact that $50.5 \%$ of the respondents were unable to give an answer to this question." 
between the poor and nonpoor, tended to come to the same conclusions. Suchman attempted to study these differences by testing the hypothesis that

- . those individuals who belong to relatively more homogeneous and cohesive groups will be more likely to react to illness and medical care in terms of the social group's definition and interpretation of appropriate medical behavior rather than the more formal and impersonalized prescriptions of the medical care system. ${ }^{15}$

Suchman's model describes two major categories of health care consumer: "cosmopolitans" and "parochials." (Suchman here acknowledges the work in this area and the terminology of Freidson ${ }^{16}$ and Gouldner ${ }^{17}$ in the development of this model.) He describes the two types as follows: - . a cosmopolitan type of social background will be more highly related to a scientific approach to health and medical care than a parochial type of background, which will be more highly related to a popular, (i.e., "lay) orientation. 18

Suchman's utilization data derived from a study of the residents of the Washington Heights area of New York City,

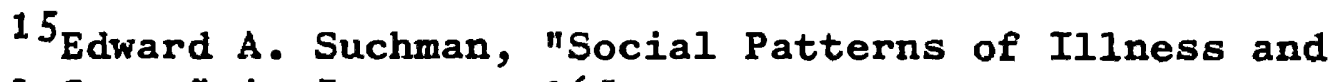
Medical Care," in Jaco, p. 265.

${ }^{16}$ Eliot Freidson, Patients' Views of Medical Practice: a Study of Subscribers to a Prepaid Medical Plan in the Bronx, (New York: Russell Sage Foundation, 1961).

${ }^{17}$ A.W. Gouldner, "Cosmopolitans and Locals: Toward an Analysis of Latent Social Roles," Admin. Science Quarter1y 2:281-306.

${ }^{18}$ Suchman, "Social Patterns of Illness and Medical Care," in Jaco, p. 265. 
a neighborhood whose racial and ethnic composition was at that time (the early 1960 's) $50 \%$ white, $25 \%$ nonwhite, and 25\% foreign-born whites. He found that utilization of preventive services in that population was more a function of socioeconomic status than of group structure or health attitudes.

In other words, Suchman's view is that social status, not the health attitudes or beliefs of the individual, determined the degree to which this population used preventive services.

\section{Brightman came to similar conclusions in his} comparison of the utilization of preventive services (i.e., adult health examinations) by ADC mothers, lowrent housing residents, and employed factory workers, 19 as did Bergner and Yerby, whose research was limited to gynecological examinations, and who considered income rather than socioeconomic status as their major variable. Their conclusions, based on U.S. statistics from 1963-1964, were as follows:

- . the proportion of the female population of obstetric or gynecologic visits in a one-year period increases sharply with increasing family income. Where family incomes are below $\$ 2,000$ only $2.8 \%$ have made such visits. At $\$ 2,000$ to $\$ 3,999,5.5 \%$ and so

${ }^{19} \mathrm{Jay}$ Brightman et al., "Knowledge and Utilization of Health Resources by Public Assistance Recipients: Public Health and Preventive Medical Resources," Amer. J. Public Health XLVIII (February 1958):197. 
on up to $12.5 \%$ at family incomes of $\$ 10,000$ and above. 20

Looking at pediatric examinations they concluded that - . at family incomes of under $\$ 2,000$, only $7.5 \%$ of the population under 17 made [a visit to a pediatrician] in a one year period. At $\$ 10,000$ and above the proportion was $33.0 \% 21$

Moody and Gray also note the failure of low income people to seek oral poliomyelitis vaccination at the same rate as more affluent members of the communities studied. Their conclusions were that the poor underutilize these services rest on the assumption that low income people suffer from "alienation" and "anomie." That is, it is not their low income or low socioeconomic status, but their failure to become socially integrated in their communities that accounts for their low rates of polio vaccination. 22 Morris et al.,in a study of the use of well-baby clinic service, came to similar conclusions. 23

Rosenstock, having reviewed the research on utilization of preventive services by low income people, draws

${ }^{20}$ Lawrence Bergner and Alonzo S. Yerby, "Low Income and Barriers to Use of Health Services," New England J. Medicine 278 (March 7, 1968):541.

\section{${ }^{21}$ Ibid.}

22 Moody and Gray, "Social Class, Social Integration, and the Use of Preventive Health Services," in Jaco, p.265.

${ }^{23}$ Naomi M. Morris et al., "Deterrents to Well-Child Supervision," Amer. J. Public Health 56 (August 1966):1232. 
the following conclusions from these and similar studies.

His conclusions summarize the "culture of poverty" view:

The findings of research on health behavior support the conclusion that there is a culture of poverty that helps to explain the health behavior of the poor. The culture of poverty may originally be based on a history of economic deprivation, but it seems to be a culture exhibiting its own rationale and structure, and reflecting a way of life that is transmitted to new generations. It is therefore suggested that while financial costs may serve as barriers to obtaining health services, their removal would probably not have the effect of creating widespread changes in the health behavior of the poor, at least not in the foreseeable future. The values for knowledge and for health exhibited by the poor, their tendency to use a shorter time horizon as a framework for planning, their reluctance to use professional referral and service systems, perhaps guided by a general feeling of powerlessness in the face of a hostile environment, all suggest that the problem of altering their behavior will prove to be highly complex and not susceptible of simple remedy.

In contrast to this view in which the low income

patient is thought to lack the capacity to adapt his or her behavior to that of more affluent health care users is the notion that the network of public and private organizations through which health care services are made available to the public lacks the capacity to adapt itself to the needs and the legitimate demands of health care consumers. Thus the "blame" for underutilization is

$24_{\text {Rosenstock, "Prevention of Illness and Maintenance }}$ of Health," in Kosa et al., p. 188 . 
placed on the "system" rather than on the individual.

This view, "rather than emphasising subjective

factors such as the extent of need or the predisposition to seek care,... stresses the potential user's structural position and hence his access to medical services." 25 Crucial to an understanding of this point of view is the concept of access, in which nonmedical barriers, such as lack of transportation, cost of babysitting, ${ }^{26}$ lack of knowledge of the availability of services, a fragmented health service delivery system, humiliating eligibility procedures, and other factors contribute to perpetuating a pattern of underutilization.

Another point that might be made here about barriers to access is that perhaps a distinction should be made between seeking a preventive physical examination and being tested, for example, for breast cancer. Friedman et al. found that even with Medicaid and the extension of health insurance to large numbers of people in recent years that women of all income groups still resist obtaining this type of preventive service. ${ }^{27}$

${ }^{26}$ Bonnie Bullough, "Poverty, Ethnic Identity, and Preventive Health Care," J. of Health and Social Behavior 13 (December 1972): 347 .

27 Bernard Friedman et al., "The Influence of Medicaid and Private Health Insurance on the Early Diagnosis of Breast Cancer," Medical Care 11 (November-December 1973):485-490. 
Coburn and Pope, in their study of Canadian working men in British Columbia, while corroborating Moody and Gray's conclusions by suggesting that "social participation" was "the most promising of the explanatory variables" that might explain differential utilization rates of preventive health examinations between different socioeconomic classes, came to another interesting conclusion. Their suggestion was that high socioeconomic status employed men can more easily take time off from work without loss of income than can lower socioeconomic status men. This suggests that it may not be the internalized attitudes of low income and low socioeconomic class people so much as it may be the circumstances of their working lives that affect their rates of utilization of preventive services. ${ }^{28}$

A study conducted in Portland, Oregon, in which low income families were integrated into an existing comprehensive prepaid health plan, found that when problems of access were minimized in that both the low income and general health plan members had equal access to a broad range of services, including preventive care services, that the differences in utilization rates were not great; in fact, for medical services utilization, they were almost

${ }^{28}$ David Coburn and Clyde R. Pope, "Socioeconomic Status and Preventive Health Behavior," J. of Health and Social Behavior 15 (June 1974): 77 . 
identical. 29

This suggests that while there may indeed be a "culture of poverty," and that while "psychological readiness ${ }^{30}$ to seek preventive care may still affect utilization rates, perhaps more equal access to services through financial subsidy of low income individuals, or by providing various social services that allow them to utilize "mainstream" services rather than traditional "charity" or public hospital and clinic services, may result in more equal utilization rates of preventive services for both poor and nonpoor individuals.

The next section will discuss the degree to which a specific type of social service, that is, the use of outreach workers, has been used as an intervention technique with low income health care consumers of preventive services.

${ }^{29}$ Greenlick, "Comparing the Use of Medical Care Services by a Medically Indigent and a General Membership Population in a Comprehensive Prepaid Group Practice Program, p. 200 .

${ }^{30}$ Rosenstock, "Prevention of Illness and Maintenance of Health," in Kosa et al., p. 201. 


\section{CHAPTER II}

\section{REVIEW OF THE LITERATURE: OUTREACH SERVICES}

The implication of much of the ideology behind the War on Poverty in the $1960^{\prime}$ 's was that poor people were somehow different from other Americans, and were for various reasons isolated not only from health care services but from American life generally. 31 They were therefore thought to be in need of help so that they could negotiate a health care system that was and is arranged by middle class people to serve other middle class people. 32 One program based on such an assumption was established in Portland, Oregon, through the Kaiser-Permanente Neighborhood Health Center Project. In this program

- - outreach services were based, in part, on the notion that the health care system 'reach out to poor people' and assist them to utilize health services appropriately. This philosophy assumed that, without this active assistance, poor people would not receive an adequate amount or pattern of services either because they could not cope with a complex medical care system or because

${ }^{31}$ Michael Harrington, The Other America, (New York: Penguin Books, 1963). This is one of the major points of the book.

32 Ernest Drucker, "Hidden Values and Health Care," Medical Care 12 (March 1974):266. 
they would sustain an intermittęnt, crisis-oriented pattern of health services use. 33

It was concluded that in order to help such individuals gain access to the health care system that other individuals who lived in the same low-income neighborhoods would be more able to gain the confidence of and communicate with their neighbors than were traditional professional people, i.e., doctors, nurses and social workers.

The purpose of this section is to review the studies in which indigenous nonprofessionals were hired and trained to do some of the work usually done by professionals in various health organizations. In most of the research, the health care organizations are public health clinics or hospitals that serve indigent populations. $34,35,36$ The objectives of the various outreach programs, the issues and problems

${ }^{33}$ Donald K. Freeborn et al., "Evaluating the Effects of Outreach Workers on Medical Care Utilization in the Kaiser-Permanente Neighborhood Health Center Project," (Portland, Oregon 1975).

34 Jane Luckham and David w. Swift, "Community Health Aides in the Ghetto: the Contra Costa Project," Medical Care 7 (July-August 1969): 332 .

35 Herbert $R$. Domke and Gladys Coffey, "The Neighborhood-Based Public Health Worker: Additional Manpower for Community Health Services," Amer. J. Public Health LVI (April 1966): 603.

${ }^{36}$ Jerome S. Beloff and Mieko Karper, "The Health Team Model and Medical Care Utilization," JAMA CCXIV (January 17, 1972) : 359 . 
inherent in the concept of outreach that surfaced in the course of these studies, and the outcomes in terms of utilization following the implementation of outreach programs will also be discussed.

\section{Objectives}

It is difficult to compare the various research efforts into the effectiveness of outreach programs with each other because 1) outreach in health organizations is a new technique and one that has only developed in the past ten years, and 2) the objectives and goals of the programs studies have been so different from each other that comparison is often meaningless. For example, how is it possible to compare a five-year-long study at Montefiore Hospital in New York 37 in which outreach workers were assigned to assist people to keep appointments and learn a number of technical para-nursing skills with a program in Los Angeles in which outreach workers were trained to provide patients in one clinic on one occasion with advice about home treatment for a child with an acute upper respiratory infection. 38 obviously, no such comparisons can be made.

37 Harold Wise et al., "The Family Health Worker," Amer. J. Public Health LXXX (October 1968): 1828.

${ }^{38}$ Joy G. Cauffman et al., "Community Health Aides: How Effective Are They?" Amer. J. Public Health LX (October 1970) : 1904 
In addition, in some studies the objectives of the health care program itself were so unclear or so broadly stated as to make any research conclusions meaningless and invalid, as in the case of Columbia Point in Boston ${ }^{39}$ or so specific that the results have little relevance except for a very small study population, as in the case of Wingert, Larson, and Friedman's ${ }^{40}$ work in Los Angeles in 1969 in which the research reported only on the success of counseling parents about iron deficiency anemia.

Finally, one major problem with outreach programs was the basic goal of the programs themselves. Did they exist to eradicate poverty by providing non-menial jobs for the poor? Or were they primarily established to extend demonstrably scarce health manpower and other health resources? Or were they intended to improve health care utilization patterns among traditional under-utilizers of health care, and especially preventive health care services? While no program was flawlessly conceptualized in terms of one or another of these objectives, some programs faltered because it was never made clear where the program's priorities lay.

${ }^{39}$ H. David Banta and Renee C. Fox, "Role Strains of a Health Care Team in a Poverty Community," Social Science and Medicine 6 (December 1972): 697.

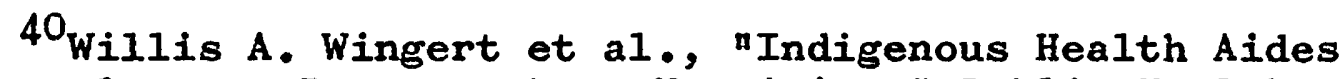
as Counselors to Parents about Nutrition," Public Health Reports LXXXIV (ApriI 1969): 328 . 
One of the clearest demonstrations of this difficulty was in the Columbia Point project.

Columbia Point, which is located in an inner-city area in Boston, was the first Office of Economic Opportunity-established health center in the U.S. It was opened in 1965, and from the outset it seemed that nothing went right. No one on the health center staff could determine precisely what the goals of the program were, and while they were honest enough to admit it, failure to agree on basic goals and objectives resulted in anxiety and low morale among professional staff. This was manifested in particular by resistance to the outreach workers. Should the Family Health Workers, as they were called, be integrated into the doctornurse-social worker teams? The social workers and nurses were agreeable to this innovative approach, but the doctors were wary and wanted to postpone such "team" efforts. And, in fact, as a result the outreach workers were not made full members of the staff for a full year after the project started. 41 Further, since the limits and definitions of both the professional staff and the outreach workers' roles were undefined, extremely stressful situations developed. Because no utilization rates were systematically recorded for patients who did and who did not have outreach workers, little is known

\footnotetext{
${ }^{41}$ Banta and Fox, p. 708.
} 
of the outreach program's impact on the community served. Particularly distressing was the issue of confidentiality. Problems in this area nearly destroyed the program because the Family Health Workers were placed in the difficult position of being at once on the staff of the health center, patients of the center, or relatives of other patients at the health center.

More recently the research has tended to shift to the opposite extreme and to be very clearly focused on specific goals and objectives. A program described by Cauffman et al., in 1970 is a good example. In research comparing professional with nonprofessional workers at the Pediatric Emergency Room of the University of Southern California Medical Center in Los Angeles they studied clinic utilization rates. The intention was to compare the rates of mothers who had talked to nonprofessional outreach workers about how to follow medical orders at home following their childrens' treatment for an upper respiratory infection with those who talked to public health nurses and to physicians. The data indicated that there was "... no evidence in the level of compliance among mothers who were instructed by community health aides, public health nurses, or physicians. ${ }^{42}$

$$
{ }^{42} \text { Cauffman et al., p. } 1907 .
$$


Outreach - Issues and Problems

The major issues and problems in outreach programs

have been:

1) the development of selection and training criteria for outreach workers;

2) the development of job skills, and the definition of the limits of professional and nonprofessional jobs; 43 and

3) the effect outreach workers have on utilization of preventive services.

Levinson and Schiller, 44 in an article describing the use of indigenous nonprofessionals in a public welfare rather than a health care setting, identify a number of problem areas that have come to researchers' attention in the course of outreach programs. While their view is, it seems to me, a negative and to some degree an elitist one, the problems they raise are interesting. They report having experienced difficulties

1) training relatively uneducated but adult persons for jobs calling for an understanding of subtle. interpersonal relationships;

$43 \mathrm{~J}$. D. Stoeckle and A. C. Twaddle, "Non-Physician Health Workers: Some Problems and Prospects," Social Science and Medicine 8 (February 1974): 71.

44 Perry Levinson and Jeffry Schiller, "Role Analysis of the Indigenous Nonprofessional, "Social Work 11 (July 1966): $96-97$. 
2) recruiting from a lower-class population noted either for its apathy or for its hostile actingout of pent-up frustration . . ;

3) getting lower-class persons to accept and use their new positions of authority with fairness, in light of their background as recipients rather than dispensers of official regulations and procedures;

4) teaching the necessity of maintaining confidentiality of information about their own neighbors and about the agency itself;

5) continuing the nonprofessionals' identity as a member of the client community in spite of his [or her] tendency to overidentify with the agency and thus become valueless as a communications link.

Kegeles, 45 in a 1969 study, also encountered serious problems in this area to the degree that "as much time was spent in personnel administration as in research administration."

Riessman, quoted by Goldstein and Camp, ${ }^{46}$ also suggests that

One of the most ignored pitfalls in selection is the stereotyped assumptions by professionals that nonprofessionals identify with the poor and possess greath warmth and feeling for them .. [Many indigenous nonprofessional health workers] see themselves as being different from their neighbors and actually have negative attitudes toward them.

45 Stephen S. Kegeles, "Problems of Experimental Research in the Urban Ghetto," Medical Care 7 (September-0ctober 1969): 404 .

${ }^{46}$ Arnold D. Goldstein and Bonnie W. Camp, "A Procedure for the Selection of Nonprofessional Workers," HSMHA Health Reports LXXXVI (June 1971): 533 . 
Developing a set of job skills for outreach workers has been another area in which programs differed, both in their objectives and in their outcomes. Kent and Smith 47 in a Denver Maternal and Infant Care Project saw the outreach workers as "semi-independent" workers on whom "subprofessional" tasks were not imposed.

Consistent with the action orientation of the indigenous worker, 'doing' and not 'talking' was the emphasis . . Formal classroom sessions and reading assignments were conspicuously absent in the training program, [which tended to be] a continuous problem-oriented process and not a structured program terminated at a certain point.

Wingert, Larson, and Friedman's ${ }^{48}$ job development

objectives were far less vague and unfocused: their intent was only to train outreach workers specifically to counsel parents about iron deficiency anemia in children.

Moore and Stewart's ${ }^{49}$ program involved an eight-day

47 James A. Kent and C. Harvey Smith, "Involving the Urban Poor in Health Services through Accomodation: the Employment of Neighborhood Representatives," Amer. J. Pub. Health LVII (June 1967): 999 .

${ }^{48}$ Willis A. Wingert et al., "Indigenous Health Aides as Counselors to Parents about Nutrition, "Public Health Reports LXXXIV (April 1969): 328.

${ }^{49}$ Frank I. Moore and James C. Stewart, Jr., "Important Variables Influencing Successful Use of Aides." Health Services Reports LXXXVII (June-July 1972): 555. 
orientation followed by the assignment of a specific task, namely: asking residents of assigned low-income neighborhoods to visit a public immunization clinic. More recently, Wingert et al., 50 in research conducted at the Los Angeles County-University of Southern California Pediatric Outpatient Department in 1975 studied the effect Chicano and black outreach workers had on utilization of clinic services in comparison with public health nurses who were providing similar services. The nonprofessional workers were assigned specific tasks but were also allowed to work somewhat autonomously under the supervision of a public health nurse.

Wise, however, in a long range study conducted at Montefiore Hospital in New York found that although outreach workers there did receive fairly specific training, especially in the area of home visit nursing (under the supervision of a public health nurse) that - - as team members they were often perceived as little more than messengers or lowlevel aides, ąnd their newly-acquired skills were not utilized. 51

${ }^{50}$ Willis A. Wingert et al., "Effectiveness and Efficiency of Indigenous Health Aides in a Pediatric Outpatient Department," Amer. J. Pub. Health LXV (August 1975): 849 .

$51_{\text {Harold Wise et al., Making Health Teams Work }}$ (Cambridge, Mass: Ballinger, 1974), 285 . 
This of course raises the question of professional resistance to outreach workers and problems created when professionally unqualified individuals assume duties and responsibilities traditionally assigned to professionals. This problem was noted earlier in Banta and Fox's work at Columbia Point.

Interestingly, the one program in which this role separation between professionals and nonprofessionals was most successful was the Montefiore Hospital project described by Torrey, Smith, and Wise 52 While at the outset of the program they report a certain vagueness in the role definition of the outreach workers, and assumed that they would be doing "social advocacy" or "health education," in fact after five years in the program, the area in which both the outreach workers and the community served by the project felt the workers had the most credibility and the greatest expertise was in home nursing. The exceptionally low turnover rate of the outreach worker over this five-year period, combined with the fact that nine members of this group received additional training in nursing-related areas, suggests that at least in

52 E. Fuller Torrey et al., "The Family Health Worker Revisited: a Five-Year Follow-Up," Amer. J. Pub. Health LXII (January 1973): 71. 
this program, nursing was a professional group that was less resistant to and less threatened by the outreach workers than the social workers and physicians who were involved in the program.

But the final question is, were the outreach workers in any of these programs effective in the sense of causing changes in health care utilization patterns of the poverty populations they served? While it appears that they were, from the point of view of methodology, it is not clear whether increased utilization was caused only by the intervention of outreach workers. A11 that can be said is that there is some evidence that possibly in combination with other unknown variables that use of outreach workers was associated with increased utilization of preventive services by low-income populations.

Luckham and Swift's $s^{53}$ research on an outreach program that was directed toward immunizing children with measles raccine was conducted at the Contra Costa County (California) Health Department. They trained health aides to make home visits in a black working-class neighborhood to acquaint families with the availability of the

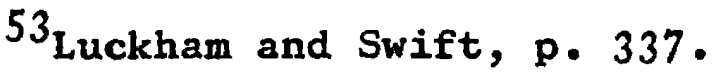


vaccine, and noted that of the families visited $25 \%$ came to the "next scheduled immunization clinic and requested measles vaccine."

The work of Diehr et al., 54 with the Model Cities Prepaid Health Care Project population in Seattle was a carefully measured attempt to study utilization changes as a result of outreach services. Unlike some of the earlier studies, this research was not done on poverty populations who are treated by public hospitals and clinics that traditionally serve low-income people but on inner-city groups who were given access to two "mainstream" comprehensive prepaid health insurance organizations, King County Medical (a combined Blue Cross-Blue Shield health plan) and Group Health Cooperative of Puget Sound (a multi-specialty group practice organization much like Kaiser in Portland and elsewhere). While both of these programs offered complete medical care, "an important goal of the outreach program was to encourage continuity of medical care and to educate families in illness prevention and health maintenance." 55

54 Paula Diehr et al., "Access to Medical Care: the Impact of Outreach Services on Enrollees of a Prepaid Health Insurance Program," J. of Health and Social Behavior 16 (September 1975): 334 . 
They indicate that while.. "the outreach group reported a greater volume of physician contacts than the non-outreach group, this was not supported by provider data." 56 In addition, they found that

- . enrollees with an outreach worker had more information about support services that would facilitate access. 5

However, despite reservations, they conclude that the data support the idea that outreach services played a role in facilitating access to care in this program. Their conclusions are thoughtful and cautiously put, and indicate the problems that make research in this area so difficult:

First [they concede] the individuals enrolled in the program were not typical poverty individuals . - . since most were employed [and] had incomes above the poverty limit . . Second, the focus of this article on the recipients of care, rather than on the outreach program itself, does not show what in the broad spectrum of services provided by the ${ }^{\text {workers }}$ was effective in increasing access. 58

In short, in the absence of outreach programs, a great deal of research indicates that poverty populations have tended to under-utilize preventive services. Moody and Gray, for example, say that this is due to

$$
\begin{aligned}
& 56_{\text {Ibid., pp. } 338-339 .} \\
& 57_{\text {Ibid., p. } 339 .} \\
& { }^{58_{\text {Ibid. }}}
\end{aligned}
$$


"alienation and anomie, "59 among other things. However, when outreach programs are in fact associated with increased utilization of these and other services, as Diehr et al., point out, so many other variables may be involved that it is difficult to demonstrate that it was indeed the presence and the efforts of the outreach workers that caused increased utilization.

In conclusion, it should be emphasized that some of the early, that is, mid-60's outreach programs were poorly conceptualized and planned and as a result researchers have been unable to draw valid conclusions on the effect of this new technique of intervention on low income consumers of preventive health care services. However, since that time both the programs and the research studies have gradually become more sophisticated, with the result that the conclusions are now less often based on data of dubious validity because of the methodological shakiness of the research design.

The following chapters will discuss a program in which the intent has been to control a greater number of variables than has been the case in other studies.

${ }^{59}$ Philip M. Moody and Robert M. Gray, "Social Class Social Integration, and the Use of Preventive Health Services, " in Patients, Physicians, and Illness, ed. E. Gartly Jaco (New York: The Free Press, 1972), p. 261 . 


\section{CHAPTER III}

\section{DESCRIPTION OF THE STUDY POPULATION \\ AND RESEARCH OBJECTIVES}

\section{DESCRIPTION OF THE STUDY POPULATION}

\section{A. INTRODUCTION}

The population of this study consists of members of the Oregon Region of the Kaiser-Permanente Medical Care Program, a prepaid medical plan in which

\footnotetext{
- - medical personnel, practicing full time in an integrated hospital/ambulatory care system, provide comprehensive medical services within the context of group practice.
}

In 1972 , the year in which these data were collected, the program enrolled approximately 200,000 subscribers, or $15 \%$ of the residents of the Portland area. Most members of the plan obtain the major part or all of their medical care from this one source. 2

${ }^{1}$ Donald K. Freeborn et al., "Health Status, Socioeconomic Status, and Utilization of Outpatient Services for Members of a Prepaid Group Practice." (Accepted for Publication in Medical Care, 1976).

${ }^{2}$ Clyde $R$. Pope et al., "Use of Outside Physicians by Members of a Group Practice Prepayment Plan." Presented at the looth Annual Meeting of the American Public Health Assn., Atlantic City, N.J., (November 1972). 
In this system a central medical record is continuously maintained for all subscribers from the time they join the plan. This record is updated after every contact and is available to the physician each time the subscriber uses the system's services. The data thus collected on each individual health plan member are made available to the Health Services Research Center, associated with the Kaiser-Permanente Medical Care Program, which conducts longitudinal and cross-sectional health services research. The Research Center has established a computerized record-keeping system from which membership, utilization, financial, and medical care data are routinely abstracted and maintained for research purposes. 3

This study will consider two major populations of the Kaiser-Permanente population: the OEO Neighborhood Health Center health plan members and a $5 \%$ random sample of the nonpoverty general health plan membership. The OEO group was further subdivided into a subgroup that was assigned Neighborhood Health Coordinators and a group that was not assigned Coordinators. There were 5,450 individuals with at least one month of health plan coverage in the "with

3 Merwyn R. Greenlick et al., "Determinants of Medical Care," Health Services Research (Winter 1968): 300 . 
coordinator" sample, 1,554 individuals with at least one month of health plan coverage in the "without coordinator" sample, and 10,255 individuals with at least one month of health plan coverage in the $5 \%$ general health plan sample. The criteria for selection of these groups will be discussed later in this chapter.

\section{B. THE OEO-NEIGHBORHOOD HEALTH CENTER PROJECT 4}

The Kaiser-Permanente Neighborhood Health Center Project, on which this study was based, was started in 1967. One of the major goals of the program at that time was to give the poverty (NHC) population the same access to the medical care services provided by an urban comprehensive prepaid group practice medical care organization that was available to the nonpoverty members of this plan. In such a setting

\footnotetext{
- . care is provided without significant financial barriers, the characteristics of the populations at risk are identifiable and medical cafe utilization behavior can be accurately recorded.

In this Project, the NHC members were regarded much the
}

$4_{\text {This program was initiated by the Office of Economic }}$ Opportunity, but by 1972, funding had been transferred to the Department of Health, Education \& Welfare. The original "OEO" designation has been used in this paper.

5 Merwyn R. Greenlick et al., "Comparing the Use of Medical Care Services by a Medically Indigent and a General Membership Population in a Comprehensive Prepaid Group Practice Program." Medical Care 10 (May-June 1971): p. 188. 
same as any other group, such as a union, school district, or government agency that might wish to enroll its members in the Kaiser-Permanente Medical Care Program: prepaid capitation rates were determined, the medical care services to be provided were agreed upon jointly by OEO, Portland Metropolitan Steering Committee (the local community action agency that was the grantee for the OEO funds), and the Kaiser-Permanente Medical Care Program administration. The NHC members were then issued identification cards exactly like the cards issued to the general membership. Attempts were specifically made not to identify the NHC group with, for example, health plan identification cards of another color than general membership cards, or with "OEO" prominently marked, or with other possibly stigmatizing features that might result in staff's differential treatment of the NHC group. 6 The only "mark" on the card that identified the NHC members was that the health plan coverage was denoted as "BH." 7

${ }^{6}$ Interview with Theodore J. Colombo, NHC Project Program Administrator 28 (Apri1 1976).

${ }^{7}$ Kaiser-Permanente Medical Care Program coverages in Portland were at that time BA, BB, BC, and so on. The letter "B" indicated the basic "package" of health plan benefits; "H" was the letter assigned to the specific additional benefits received by the poverty population. While these letters had no particular meaning to Kaiser-Permanente Medical Care Program administration, the community began to and continues to interpret the letters "BH" as "Better Health," as "Are you in the Better Health project?" 
The only difference between the general health plan sample group and the NHC group was that while the general membership's premium fees were paid by the employer of an enrolled group, or jointly by the employer and the employee, the premium fees for the NHC population were paid by OEO, and later by the Department of Health, Education \& Welfare.

\section{CHARACTERISTICS OF THE NHC POPULATION AND CRITERIA FOR SELECTION}

The NHC population itself was identified in the following way:

Since it was estimated that approximately 4,000 families who lived in the target areas met eligibility criteria and only. 1,200 could be served, it was necessary to establish selection priorities. The - . first priority was the care of large families with small children. The next priorities, in order,

$8_{\text {The target area neighborhoods, located in Southeast }}$ Portland, were identified and selected by the Portland Metropolitan Steering Committee in 1966. They were Albina, Brooklyn, Buckman, Sunnyside, and Richmond. In 1969 a number of other neighborhoods were added (St. Johns, Columbia Villa, Lents, Errol Heights, and several poverty areas on the West Side of Portland.) Since the NHC Project members tended to move frequently, and become dispersed throughout the Portland area, by 1973 membership was extended to eligible individuals and families living anywhere in Multnomah County. Although at the outset of the program the outreach workers, called Neighborhood Health Coordinators, were assigned to work in particular neighborhoods, this became confusing when the subscriber families moved. In 1972 this situation had stabilized as follows: when a family moved, they not only continued in the NHC program, but kept the same coordinator, which maintained continuity of services. Interview with Theodore J. Colombo, 5 (May 1976). 
were families with known acute health problems, but with no existing medical care source; young couples or unwed mothers; and families with members in the age group of 45 to 64 . The predominant number of families eventually selected were in the first and second priority categories. 9

Compared with the sample of the health plan population, then the NHC population was "younger . . and contained a higher proportion of women. 10

Other significant differences between the two populations were as follows:

- - only $22 \%$ of the persons in the health plan sample were in families with a female subscriber or head, but more than $55 \%$ of the OEO population was in families headed by a female... reside in the core city - . [but only] $25 \%$ of the
health plan sample live in the core city, with $38 \%$
[living] elsewhere in the city and $37 \% .$. . out-
side the city limits.

${ }^{9}$ Theodore J. Colombo et al., "The Integration of an OEO Health Program into a Prepaid Comprehensive Group Practice Plan." Amer. J. Pub. Health LIX (April 1969): p. 644 .

10 Merwyn R. Greenlick et al., "Comparing the Use of Medical Care Services by a Medically Indigent and a General Membership Population in a Comprehensive Prepaid Group Practice Program." p. 188 .

${ }^{11}$ Colombo estimated that $50-60 \%$ of the NHC Project families were welfare, that is, AFDC-eligible.

12 Merwyn R. Greenlick, "Comparing the Use of Medical Care Services by a Medically Indigent and a General Membership Population in a Comprehensive Prepaid Group

Practice Program." p. 188-189. 


\section{THE NHC PROJECT OUTREACH PROGRAM}

The Outreach Program itself was established according to the Office of Economic Opportunity Health Services Program Guidelines, which specified that

[which] extend to follow-up on all persons cared
for in the program [and] - i transportation to
help eligible individuals to travel to the source
of service.

would be provided. 13

As a result, the range of outreach services that were provided in Portland to the Project in 1972 included

transportation, the services of nonprofessional health workers (called Neighborhood Health Coordinators), and supporting professional and administrative personnel and services. The[se] outreach services were added to the existing Kaiser-Permanente Medical Care Program and were available only to the poverty population.

\section{THE NEIGHBORHOOD HEALTH COORDINATORS}

Specifically, the duties and responsibilities of the twenty coordinators, who were themselves recruited from the OEO target area and were chosen by Portland

13 Guidelines; The Comprehensive Neighborhood Health Services Program, Health Services Office, Community Action Program, Office of Economic Opportunity, Washington, D.C., (March 1968).

${ }^{14}$ Donald K. Freeborn et al., "Evaluating the Effect of Outreach Workers on Medical Care Utilization in the Kaiser-Permanente Neighborhood Health Center Project," (Portland, Oregon 1975), p. 1. 
Metropolitan Steering Committee, were as follows:

to recruit participants to the Project; 15

to teach participating family members ${ }^{\text {the }}$ value of good health and health practices;

to motivate persons to utilize health services appropriate to their needs;

to aid members in participating effectively in the Kaiser-Permanente medical care system;

15 Merwyn R. Greenlick, "Medical Services to Poverty Groups," p. 141 in "The Kaiser-Permanente Medical Care Program: a Symposium, ed. Anne R. Somers. New York: The Commonwealth Fund, Inc., 1971.

"The Coordinators began [to search for eligible families] by obtaining names. . from other OEO projects, neighborhood service centers, schools, churches, Head Start Programs, and traditional social welfare agencies. When these sources of referral were exhausted, the coordinators began a house-to-house canvass in their neighborhood, explaining the Project and accepting applications from those families interested in participating."

16 Thomas L. Milne, "A Drug Education Program for Community Outreach Workers," J. Amer. Pharmaceutical Assn., (September 1972): 456. Milne investigated the extent to which misconceptions about drugs among the coordinators themselves affected their ability to teach the NHC population about appropriate drug use. He found that a number of misconceptions were prevalent. It was found that they thought that

"the daily administration of laxatives to young children [was necessary] because of a widely-held belief in the necessity of daily bowel movements;

- . "natura1" drugs are superior in quality and activity to the corresponding "synthetic" drugs;

[it was a good idea to discontinue] antibiotic drug therapy with the disappearance of symptoms." 
to direct families to community resources for other nonmedical problems common to an indigent population.

A number of studies conducted before the Neighborhood Health Center Project was started showed that poverty populations have traditionally under-utilized preventive health services compared with other Americans. 18,19 It was theorized that this may have been due in part to the barriers the poor face when they seek health care. As a consequence, one of the coordinators' major functions was seen as helping this population overcome these barriers.

Thus one measure of the Project's effectiveness was the degree to which the NHC population who had coordinator services had as high or higher rates of utilization of the three types of preventive services being studied as those who did not have the coordinators' services. In this study,

${ }^{17}$ Donald K. Freeborn et al., "Evaluating the Effect of Outreach Workers on Medical Care Utilization in the Kaiser-Permanente Neighborhood Health Center Project," pp. 2-3.

18 Anselm Strauss, "Medical Ghettoes," in Patients, Physicians, and Illness, ed. E. Gartly Jaco, (New York: The Free Press, 1971, 2nd ed.) Strauss suggests that the medical care system, i.e., hospitals, doctors, etc., is itself a barrier to access for low income people because the system was arranged by and for middle income people rather than for the poor.

${ }^{19}$ Irwin M. Rosenstock, "Prevention of Illness and Maintenance of Health," in Poverty and Health, ed. John Kosa et al., (Cambridge, Mass: Harvard University Press, 1969). 
then, high utilization is not much so much regarded as a measure of illness in the community, since preventive care is by definition not a response to illness behavior, so much as it is a reflection of the capacity of urban indigent people who were presumably not familiar with any form of regular "mainstream" medical care to adapt their behavior so that they could use the preventive health care services provided within the Kaiser system.

\section{SELECTION OF THE "WITH AND "WITHOUT COORDINATOR" POPULATIONS}

At the beginning of the Project in 1967 all members of the NHC population were assigned Neighborhood Health Coordinators. However, in order to study the impact these indigenous nonprofessional workers were having on utilization rates, if any, in September 1969 the NHC population was divided by means of a random sampling technique into three groups. Fifty percent retained the coordinators who had been assigned to them at the outset of the program (or, if they were new enrollees, a coordinator was assigned). Another $25 \%$ remained in the coordinator's caseload (an average of 60 families per coordinator) ${ }^{20}$ if they had previously been enrolled (or, if they were new enrollees they were assigned a coordinator, but told that outreach services were 
available only if specifically requested by the subscriber). The remaining $25 \%$ were not assigned coordinators.

By 1972 all of the group of NHC health plan members had coordinators, and most of those in the second and third groups did not have coordinators who actively sought them out. While it is possible that some of the original NHC families who joined the Project in 1967 might have had coordinators assigned, and then have been moved later to the "without coordinator" group (but still had assigned coordinator), it is thought by the program's administrators that the number of families who, despite their no longer having coordinator services, still might have maintained contact with their former coordinator, is small. ${ }^{21}$

Thus, for the purposes of this study, the first NHC poverty group is regarded as having had coordinator services in 1972; the second and third groups were combined into one group that was regarded as not having had coordiservices in 1972 .

E. CHARACTERISTICS OF THE 5\% SAMPLE OF THE GENERAL HEALTH PLAN MEMBERSHIP

Research utilization data are continuously obtained

${ }^{21}$ Donald K. Freeborn et al., "Evaluating the Effect of Outreach Workers on Medical Care Utilization in the Kaiser-Permanente NHC Project," p. 7. 
on a random sample of the general health plan membership.

The sample was obtained in the following way:

the sampling method used approximated a two-stage probability sample. A 5\% sample of family units (the primary sampling unit was selected by computer, using a simple random sampling technique. These units (approximating primary families) provide natural clusters of individual elements. Because many medical care phenomena are essentially family-oriented, all the individuals (elements) in the cluster are included in the sample. This is equivalent to subsampling with a sampling fraction of one in the second stage and provides an equal probability cluster sample of the Plan population, allowing estimates of utilization to be made on either a family or an individual basis when the appropriate variance formula is used. 22

The present study compares rates of utilization by individuals rather than family units.

The original sample was taken in September 1969, and

is updated as follows:

each month a sample of $5 \%$ of all new families is added to the overall sample. Attempts are made to record continuous medical care utilization of those who have dropped out of the Health Plan, but the overall sample is designed to represent the overall Health Plan membership at any point in time.

The general health plan membership is a highly diverse and heterogeneous population, and is very similar to the

22 Merwyn R. Greenlick et al., "Determinants of Medical Care," Health Services Research (Winter 1968): 299.

${ }^{23}$ Ibid., p. 300 . 
population of the Portland Standard Metropolitan Statistical Area. 24

\section{RESEARCH OBJECTIVES}

The major research question is: did the use of Neighborhood Health coordinators in the poverty groups appear to cause changes in preventive health care behavior as manifested by changes in preventives services utilization rates? And further, how do the utilization rates of the poverty groups compare with those of the general health plan sample? Are they the same? Or different?

This study has the following specific objective: to determine the utilization rates of primary immunizations, preventive physical examinations, and Pap smears in each of the three study groups (those who did and did not have coordinator services, and the $5 \%$ health plan sample), and to compare the rates of the two poverty groups with each other, and with the $5 \%$ sample, controlling for age and sex. This overall objective gives rise to a number of related questions, to wit:

${ }^{24}$ U.S. Department of Health, Education \& Welfare, Health Services and Mental Health Administration. Health Maintenance Organization Service, Public Health Service, Some Information Descriptive of a Successfully Operating Health Maintenance Organization, by Ernest Saward, Janet Blank, and Henry Lamp, Publication Number (HSM) 73-13011. (Rockville, Md.: Government Printing Office, 1973), p. 8. 
A. Are individuals in the Neighborhood Health Center "with coordinator" group more likely to seek primary immunizations than those in the "without coordinator" group? or less likely? How is this reflected in the utilization rates?

B. Are individuals in the Neighborhood Health Center groups more likely to seek primary immunizations for their children, or for themselves? Or are they less likely to do so?

C. Are individuals in the "with coordinator" group more likely to seek preventive physical examinations than those in the "without coordinator" group? or less likely? How is this reflected in the utilization rates?

D. Are individuals in the Neighborhood Health Center groups more likely to seek preventive physical examinations for their children than for themselves? or less likely? That is, in which age groups do the bulk of preventive physical examinations occur?

E. Are individuals in the "with coordinator" Neighborhood Health Center group more likely to have Pap smear tests taken than those in the "without coordinator" Neighborhood Health Center group? or less likely? How do the rates differ?

F. Looking at two of the three measures, i.e., 
primary immunizations and preventive physical examinations, are the rates of males and females similar? or different?

G. Finally, how do the Neighborhood Health Center groups' rates, using each of the three measures, compare with the rates of the general health plan membership sample? That is to say, do outreach services, after one has controlled for age, sex, and equal access to services, appear to raise utilization rates to those of the "average" health plan members' rates? or not? (This of course assumes that the poverty groups' rates are lower than those of the general health plan membership sample.)

III. MEASURES AND DATA SOURCES

This study has been limited to three measures of preventive health care behavior: primary immunizations, preventive, i.e., non-disease physical examinations, and Pap smears.

\section{A. MEASURES}

\section{PRIMARY IMMUNIZATIONS}

Primary immunizations are defined as the basic "package" of inoculations that are given children and adults as needed within the Kaiser-Permanente Medical Care Program. This measure consists of diptheria, pertussis, tetanus (DPT), poliomyelitis, smallpox, and measles vaccines. This is 
largely a child-centered program, and while subscribers new to the system are referred for immunizations they may have failed to obtain prior to their joining Kaiser-Permanente, the majority of these immunizations take place in this health care system in the first four years of life. It should be noted that immunizations given adults who want a tetanus inoculation after stepping on a rusty nail, for example, are called "secondary immunizations," and are not included in this study.

\section{PREVENTIVE PHYSICAL EXAMINATIONS}

These consist of regular examinations given where disease is not present or suspected. This is the category into which "well-baby," "well-child," and "yearly checkups" for adults fall.

\section{PAPANICOLAOU SMEARS}

The Papanicolaou, or Pap smear, a routine test given to women, checks for the presence of abnormal cells in the cervix that indicate the possible presence of cancer of the cervix.

\section{B. DATA SOURCES}

The data on which this study is based were derived from the medical records of the $5 \%$ sample of the general health plan membership described earlier in this chapter. It is obtained in the following way: 
For individuals in the $5 \%$ sample, research medical technicians routinely record medical care data. Data for each contact include time, place, type of service, . . and type of provider . . information on episodes and the content of each visit. These data are compu- 25 terized and the file is continuously updated. 25

\section{TABLES}

The tables represented in Tables $1,2,3$, and 4 record, controlling for age and sex in all populations, (the two subgroups of the poverty populations and the 5\% general health plan sample), the rates of utilization for these three measures of preventive health care.

\section{D. "PERSON/YEARS"}

The concept of "person/years" has been used to allow comparisons across these population groups. As described elsewhere

the procedure required the summation of the total months of Health Plan eligibility for each person during the 12-month observation period. The sum was divided by 12 months to obtain the total number of person/years of eligibility during the study period.

25 Donald K. Freeborn et al., "Health Status, Socioeconomic Status, and Utilization of Outpatient Services for Members of a Prepaid Group Practice," pp. 4-5.

${ }^{26}$ Donald K. Freeborn et al., "Evaluating the Effect of Outreach Workers on Medical Care Utilization in the Kaiser-Permanente Neighborhood Health Center Project," p. 9 . 
Since all these three populations contain members who for one reason or another were not members during the entire period between January 1, 1972, and December 31, 1972 (e.g., they joined in April, or left the Portland area in July, or died in November), the idea of person/years was introduced so that the number of persons who actually received services during that year could be measured with some degree of confidence that the same number of persons were in fact being compared. 
CHAPTER IV

\section{FINDINGS AND DISCUSSION}

\section{PRIMARY IMMUNIZATIONS}

A. THE "WITH COORDINATOR POVERTY GROUP COMPARED WITH THE "WITHOUT COORDINATOR" POVERTY GROUP

This measure of preventive health care utilization is one in which the highest rates occur in the age group 0-4 for both males and females in both the "with coordinator" and "without coordinator" populations. These high utilization rates ( 167.52 and 134.80 for males, and 160.75 and 133.22 for females) suggest that primary immunizations are seen by the subscribers (and by the Kaiser-Permanente organization) as very important for children in the first four years of life. These rates, which decline sharply in the next age group (5-9), the rates in the 5-9 group being $1 / 4$ to $1 / 3$ of those in the 0-4 group, dwindle to almost nothing in the age group $20+$ for both males and females. This is not surprising, and simply reflects the fact that primary immunizations are an infant- and child-centered measure of preventive care. Looking at the age group $0-4$, the differences between the rates of the "with" and "without coordinator" groups for both males and females are striking. The rates for both males and 
females in the "with coordinator" group are higher than those in the "without coordinator" group. For males the "with coordinator" group's rates are 167.52 per hundred person/years; for the "without coordinator" group the rate is 134.80. Thus, for males aged $0-4$ the "with coordinator" group's utilization rate, using the measure of primary immunizations, is $24 \%$ higher than the rates of the "without coordinator" group.

This finding suggests that the services of a coordinator were associated with higher utilization rates for primary immunizations in the age group 0-4 for both males and females.

There appear to be no conclusions of consequence to be drawn from the data on males and females above age 4 , except to note that the rates for females tend to be slightly higher than those for males, that after age 4 rates in both the "with" and "without coordinator" groups drop off sharply, and that after age 20 the rates become so low as to be negligible.

B. THE NHC (POVERTY) GROUPS COMPARED WITH THE $5 \%$ GENERAL HEALTH PLAN SAMPLE GROUP

The rates in age group $0-4$ for both males and females, given the measure of primary immunizations, seem to follow a progression: for males the "without coordinator" group is lowest, at 134.80; the "with coordinator" group is next highest, being 167.52 or $24 \%$ higher than the "without coordinator" group's rates; and the $5 \%$ sample group is the highest, being 
17\% higher than the "with coordinator" group of the poverty population. For females they are $133.22,160.75$, and 200.36 respectively. This suggests that outreach services had a substantial measurable impact on primary immunization utilization rates, but that they were not sufficient to raise those rates to those of the $5 \%$ health plan sample. This indicates that as an intervention technique with the poverty population being studied, outreach services might be said to have been effective, at least in 1972 .

In the age group $20+$ the rates for the health plan sample group and the two poverty groups are approximately the same (between 2 and 4 per hundred person/years in the health plan sample group, and between 2 and 3 in the poverty groups), and so small as to be almost negligible. However, the samples are too small to make it possible to draw valid conclusions from these data.

\section{PREVENTIVE PHYSICAL EXAMINATIONS}

A. THE "WITH COORDINATOR" POVERTY GROUP COMPARED WITH THE "WITHOUT COORDINATOR" POVERTY GROUP

The highest rates of utilization, using the measure of preventive physical exams, and controlled for age and sex, are concentrated in the age group 0-4 for both males and females in both the "with" and "without coordinator" populations. The rates for this age group are roughly between 2 and 4 times as high as for any other age group. What this 
means is that this health plan provides the greatest proportion of its preventive physical examinations to individuals in the first four years of life.

Again, as in the case of primary immunizations, the rates for both males and females aged 0-4 in the "with coordinator" group are higher than those in the group that did not have the services of a coordinator. The rate for males is 93.80 , as opposed to 87.29 per hundred person/ years, or $7.5 \%$ higher in the "with coordinator" group than in the "without coordinator" group; however, the rate for females is 105.38 , as opposed to 78.67 per hundred person/years, or almost 34\% (33.95\%) higher in the "with coordinator" group than for the "without coordinator group. This large difference in the rates between males and females is quite puzzling: it seems implausible that the parents of females aged $0-4$ should be more influenced by the coordinators than the parents of males in the same age group, but that appears to be the case. The rates of preventive physical examinations, like those for primary immunizations, decline precipitously after age 4 for both males and females in the "with" and "without coordinator" groups (as well as in the 5\% sample). However, the rates for males are in general lower than those for females. That is to say, between age 5 and age 49 , the rates for males range in the area from 
10 to 28 per hundred.person/years in both the "with" and "without coordinator" groups; for females between age 5 and age 49 the range is between 21 to 38 per hundred person/years. This finding indicates that in general women in both the "with" and "without coordinator" groups tend to have consistently more preventive physical examinations throughout their lives than men do. This finding has been borne out by other studies ${ }^{1}$ and it suggests that women may be more health-conscious and interested in maintaining their health than men. It is not clear why this should be so.

Looking at the differences between the "with" and "without coordinator" groups, the rates of the males in the "with coordinator" group were higher than those of in the "without coordinator" group in only 3 of the 13 age groups after age 4; the rates of the females in the "with coordinator" group were higher than those in the "without coordinator" group in 8 of the 13 age groups after age 4 . These findings suggest that, using the measure of preventive physical examinations that outreach services

${ }^{1}$ Merwyn R. Greenlick et al., "Comparing the Use of Medical Care Services by a Medically Indigent and a General Membership Population in a Comprehensive Prepaid Group Practice Program," p. 197. 
had some impact on males and females in the 0-4 group and less impact on males and females in the other age groups.

\section{B. THE NHC (POVERTY) GROUPS COMPARED WITH THE} 5\% GENERAL HEALTH PLAN SAMPLE GROUP.

Comparing the NHC group with the $5 \%$ general health plan sample group, again looking at the 0-4 age range in which the greatest number of preventive physical examinations (in terms of person/years) occurs, the rates of both poverty groups are lower than those of the health plan sample. What the data seem to show, for age $0-4$ males and females, is that outreach services did raise utilization rates among poverty population members, but not so that they equal the rates of the $5 \%$ sample. For males in the 0-4 age group, the rates of utilization are 93.80 per hundred person/years for the "with coordinator" group, compared with 130.99 per hundred person/years for the nonpoverty group. That is, the rates of the nonpoverty group are $40 \%$ higher than those of the "with coordinator" poverty group.

The same general finding holds true for females as well, where the comparable rates for females aged $0-4$ are 142.84 per hundred person/years in the health plan sample, and 105.38 per hundred person/years in the "with coordinator" group. The health plan sample group's rates are $36 \%$ higher 
than the rates of the "with coordinator" group. However, comparing the health plan sample females with the females aged 0-4 who did not have coordinator services, the health plan sample's rates are $82 \%$ higher. What these data suggest is that the Neighborhood Health coordinators were instrumental in raising utilization rates for women in the "with coordinator" group substantially (by 36\%), but the coordinators (perhaps combined with other unknown variables) were unable to raise the rates to those of the health plan sample.

Other interesting patterns should be noted. The health plan sample group's rates overall exceed those of the "with coordinator" group in 12 of 14 age groups for both males and females. However, the rates of the "with coordinator" group females tend to be far closer to those of the $5 \%$ sample than are those of the "with coordinator" group males to those males in the 5\% sample. The rates of females in the $5 \%$ sample range from a low of 28.30 to a high of 49.95 per hundred person/years; in the "with coordinator" group, by comparison, the range is from 26.50 to 40.68 per hundred person years. Finally, in the group of females without coordinators, the range is from 21.31 to 42.55 .

The major conclusion to be drawn here is that women 
in all age groups, whether or not they are from the poverty or nonpoverty populations, obtain more preventive physical examinations throughout their lives than men do. However, the differences between women's use of preventive physical examinations in the poverty group and in the health plan sample group are not substantially different. This conclusion may suggest two things: the first is that outreach coordinators did substantially raise the utilization rates of women in the 0-4 age group, although not in the other age groups, using the measure of preventive physical examinations, and controlled for age and sex; the second is that women consistently obtain physical examinations at higher rates $t_{\text {han }}$ men.

\section{PAP SMEARS}

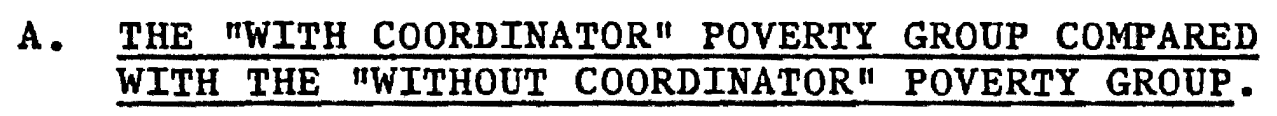

Using the measure of Pap smears, and controlling for age and sex, the rates of utilization for women in the "with coordinator" group were higher than those for the "without coordinator" group in 9 of the 12 age groups in which Pap smears were reported. The greatest difference is in the age group between 15 and 19 , where the increase is $20 \%$.

In general, however, the differences between the rates of the "with coordinator" and the "without 
coordinator" groups were not substantial, and followed no particular pattern, except in the 45-49 age group of "without coordinator" females, in which the rate is substantially (62\%) higher than those of the "with coordinator" group.

The conclusion that might be reached from looking at these data is that while outreach services are associated with higher rates of Pap smears, the differences are not striking.

B. THE NHC (POVERTY) GROUPS COMPARED WITH THE 5\% GENERAL HEALTH PLAN SAMPLE GROUP

One interesting finding is that the rate of Pap smears in the poverty populations are highest between 20 and 24 ; in the $5 \%$ sample group the age group in which the highest rates occur is between 25 and 29 .

After age 29 the 5\% group's rates decline steadily with a slight increase at age $40-44$, after which it declines again. The rates of the "with coordinator" group, by comparison, after 24 steadily declines until 60+, when it goes up slightly. The "without coordinator" group's rates are much like those of the "with coordinator" group except for a sharp increase in age group 45-49. However, the findings for ages over 49 may not be valid due to the small sample size in the "without coordinator" population. Both poverty groups' rates are higher than the genhealth plan sample group's rates until age 20-24, after 
which time they are lower in all age groups through 65+.

The conclusion that might be reached is that using the measure of Pap smears, and controlling for age and sex, outreach services are associated with some increases in utilization. 
CHAPTER $V$

SUMMARY AND CONCLUSIONS

\section{SUMMARY OF FINDINGS}

In terms of the research objective and the questions raised earlier in Chapter III a number of conclusions might be drawn from these data. (These subsections "A" - "G" refer back to those in the "Research Objectives" section in that chapter.)

A. Individuals in the "with coordinator" Neighborhood Health Center group are more likely to receive primary immunizations than those in the "without coordinator" group. This is reflected most clearly in the age group $0-4$ in which the major number of primary immunizations occur.

B. The data indicate that individuals in the poverty groups are more likely to seek primary immunizations, particularly in the 0-4 age group, than for themselves. This is not surprising, given the nature of this preventive care service, which directs itself primarily to children.

c. Looking at the measure of preventive physical examinations, individuals in the "with coordinator" Neighborhood Health Center group are more likely to seek them than the individuals in the "without coordinator" group. This 
finding is most evident in age group $0-4$, in which the utilization rates for this measure of preventive care are highest. D. Again, as in the results of the data on primary immunizations, individuals obtain more preventive physical examinations for their children than they do for themselves. This suggests 1) that the Kaiser-Permanente Medical Care Program stresses the importance of preventive services to this age group more than to other groups, and makes these services available in a way that is convenient to the subscribers, and 2) that more frequent preventive physical examinations are important to health in this age group than in other age groups. Still, it should be emphasized that the fact that infants' and adults' rates differ widely does not suggest overutilization by infants and young children and underutilization by adults.

E. In the case of Pap smears, the utilization data appear less clear. While it is true that the rates for the "with coordinator" group are higher than for those in the "without coordinator" group in nine of the 12 age groups in which Pap smears are reported, in five of those nine age groups the sample in the "without coordinator" group was too small to allow valid conclusions or generalizations to be made. Thus, a pattern demonstrating the effectiveness of outreach services on utilization rates, using the measure 
of Pap smears, is not clear.

F. In the area of primary immunizations the differences in rates between males and females are small. However, in the case of preventive physical examinations, males in all but a few age groups obtain fewer examinations than women. G. Comparing the rates of the poverty groups with those of the $5 \%$ general health plan sample, the conclusions reached are striking.

\section{Using the measure of primary immunizations,}

while outreach services can be seen to raise utilization rates above those of the Individuals who did not have outreach services, intervention by Neighborhood Health coordinators were not sufficient to raise the rates to equal those of the general health plan sample. The difference in the rates for males and females in the $0-4$ age group reflect this most clearly. For males in the "with coordinator" population the rate is 167.52 primary immunizations per hundred person/years, compared with 195.30 primary immunizations per hundred person/years in the general health plan sample group. For females the rates are 160.75 and 200.36 , respectively. The rates for males are thus $17 \%$ higher in the general health plan sample than in the "with coordinator" Neighborhood Health Center poverty groups; the corresponding rate for females is 25\% higher. 
2. A similar pattern is evident, using the measure of preventive physical examinations. For males in age group $0-4$, the "with coordinator" group rate is 93.80 preventive physical examinations per hundred person/years, compared with 130.99 examinations for the general health plan group. For females the rates are 105.38 preventive physical examinations per hundred person/years and 142.84 examinations, respectively. The rates for males are thus $40 \%$ higher in the general health plan sample than in the "with coordinator" group; the rate for females is $36 \%$ higher.

The review of the literature of preventive care showed that much of the available research data indicates that low income populations for various reasons obtain fewer preventive health services in the area of immunizations, preventive physical examinations, and Pap smears than more affluent Americans do. But, as Rosenstock points out, most of the studies

have focused specifically and exclusively on ... preventive-or diagnostic health behavior... [and] are of limited value since they were performed on relatively small samples or in highly restricted geographic regions.

This of course had made much of the research into preventive care of limited usefulness. But as was pointed out earlier, most studies of utilization of preventive health services have not included a control group from what might be 
regarded as an "average" or "normal" population for the geographical area studies, and this has caused the validity of such research to be called into question.

One of the points being made by this study is that poor people and more affluent people have different experiences when they seek health care services, including preventive health care services, and this is not only due to different barriers to access to health care, but because poor people encounter entirely different health care systems. That is, they are treated in public clinics and "county" or "charity" hospitals, as opposed to being treated in fee-for-service private hospitals and by private physicians or through some form of comprehensive prepaid health care. This paper has been an attempt to show how when low income people are integrated into "mainstream" medical care that it is possible to modify health care behavior at least to some degree by means of an intervention technique, in this case outreach services.

But there are other issues involved in the concept of preventive care. Three major areas that still need research are health outcomes, cost-effectiveness, and what might be called the problem of nutrition vs. medical care.

The first issue, health outcomes, is critical when one considers how effective a particular measure of preventive 
care is in reducing the incidence of disease. Pap smears is an obvious example. Should these tests be given routinely to all women in the United States at regular intervals? How many cases of cancer of the cervix are detected through such examinations in time to effect a favorable health outcome? Is this number sufficient to justify a policy of universal screening?

This question of course leads to the second issue, which is cost-effectiveness. Using the example of Pap smears again, how many womens' lives are prolonged and by what period of time by the early detection of this type of cancer? Given scarce medical resources, should the administration of this test take precedence over other kinds of preventive care services? In short, how much are we willing to pay? And how much illness and disease and reduced productivity, quite aside from pain and impairment of physical and psychological functioning are we willing to tolerate?

The final issue, nutrition vs, medical care, has to do partly with the individual's responsibility to keep himself or herself healthy, and partly with the problem that low income people are often unable to do so. This again presents a number of very difficult policy choices. But while these issues need systematic inquiry and require policy choices and trade-offs on the national level, they are beyond the scope of this limited study. 


\section{A SELECTED BIBLIOGRAPHY}

Banta, H. David, and Fox, Renee C. "Role Strains of a Health Care Team in a Poverty Community: the Columbia Point Experience." Social Science and Medicine 6 (December 1972):697-722.

Beloff, Jerome S., and Korper, Mieko. "The Health Team Model and Medical Care Utilization." JAMA CCXIV (January 17, 1972) : 359-366.

Bergner, Lawrence, and Yerby, Alonzo S. "Low Income and Barriers to Use of Health Services." New Engl. J. Medicine 278 (March 7, 1968):541-546.

Berkanovic, Emil, and Reeder, Leo G. "Can Money Buy the Appropriate Use of Services? Some Notes on the Meaning of Utilization Data." J. of Health and Social Behavior 15 (June 1974):93-99.

Bice, Thomas W., Eichorn, Robert L., and Fox, Peter D. "Economic Class and Use of Physician Services." Medical Care 11 (July-August 1973):287-296.

Brightman, Jay, Notkin, H., Brumfield, W.A., Jr., Dorsey, S.M., and Solomon, H.S. "Knowledge and Utilization of Health Resources by Public Assistance Recipients: Public Health and Preventive Medical Resources." Amer. J. Public Health XIVIII (February 1958): 188-198.

Broida, Joel H., Lerner, Monroe, Lohrenz, Francis N., and Wenzel, Frederick J. "Impact of Membership in an Enrolled Prepaid Population on Utilization of Health Services in a Group Practice." New Engl. J. Medicine 292 (April 10, 1975): 780-783.

Bullough, Bonnie. "Poverty, Ethnic Identity, and Preventive Health Care." J. of Health and Social Behavior 13 (December 1972):347-359.

Cartwright, Ann. Patients and Their Doctors: a Study of General Practice. New York: Atherton Press, 1967. 
Cauffman, Joy G., Wingert, Willis A., Friedman, David B., Warburton, Edward A., and Hanes, Bernard. "Community Health Aides: How Effective are They?" Amer. J. Public Health LX (October 1970): 1904-1909.

Coburn, David, and Pope, Clyde R. "Socioeconomic Status and Preventive Health Behavior." J. of Health and Social Behavior 15 (June 1974):67-77.

Colombo, Theodore J., Saward, Ernest W., and Greenlick, Merwyn. R. "The Integration of an OEO Health Program into a Prepaid Comprehensive Group Practice Plan." Amer. J. Public Health LIX (April 1969): 641-650.

Diehr, Paula, Jackson, Kathleen 0., and Boscha, M. Vickie. "Access to Medical Care: The Impact of Outreach Services on Enrollees of a Prepaid Health Insurance Program." J. of Health and Social Behavior 16 (September 1975):326-340.

Domke, Herbert R, and Coffey., Gladys. "The NeighborhoodBased Public Health Worker: Additional Manpower for Community Health Services." Amer. J. Public Health IVI (April 1966): 603-608.

Donabedian, Avedis. Aspects of Medical Care Administration: Specifying Requirements for Health Care. Cambridge, Mass.: Harvard University Press, 1973.

Drucker, Ernest. "Hidden Values and Health Care." Medical Care 12 (March 1974):266-273.

Felch, William C. "Does Preventive Medicine Really Work?" Prism 1 (October 1973):26-28.

Fink, R. "Social Research Techniques in the Study of Poverty and Nonpoverty Groups in Multiphasic Health Testing." Revision of paper presented at the 26th meeting of the American Association for Public Opinion, Pasadena, Calif., 22 May 1971.

Freeborn, Donald K., Mullooly, John P., Colombo, Theodore J., and Burnham, Vicky. "Evaluating the Effect of Outreach Workers on Medical Care Utilization in the KaiserPermanente Neighborhood Health Center Project." Portland, Oregon, 1975. 
Freeborn, Donald K., Pope, Clyde R., Davis, Maradee A., and Mullooly, John P. "Health Status, Socioeconomic Status, and Utilization of Outpatient Services for Members of a Prepaid Group Practice." Accepted for publication in Medical Care, 1976.

Freidson, Eliot. Patients' Views of Medical Practice: a Study of Subscribers to a Prepaid Medical Plan in the Bronx. New York: Russell Sage Foundation, 1961.

Freymann, John G. "Medicine's Great Schism: Prevention vs. Cure: an Historical Interpretation." Medical Care 13 (July 1975): 525-536.

Friedman, Bernard, Parker, Paul, and Lipworth, Leslie. "The Influence of Medicaid and Private Health Insurance on the Early Diagnosis of Breast Cancer." Medical Care 11 (November-December 1973):485-490.

Fuchs, Victor R. "Health Care and the United States Economic System." Milbank Memorial Fund Quarterly 50 (April 1972):229, quoted in Social Policy

(November-December 1975):2.

Fuchs, Victor R. Who Shall Live? Health, Economics, and Social Choice. New York: Basic Books, Inc., 1974.

Gartner, Alan. Paraprofessionals and their Performance: a Survey of Education, Health, and Social Service Programs. New York: Praeger, 1971.

Goldstein, Arnold D. and Camp, Bonnie W. "A Procedure for the Selection of Nonprofessional Workers." HSMHA Health Reports 86 (June 1971): 533-536.

Gouldner, A.W. "Cosmopolitans and Locals: Toward an Analysis of Latent Social Roles." Administrative Science Quarterly 2:281-306.

Greenlick, Merwyn R. "Comparing the Use of Medical Care Services by a Medically Indigent and a General Membership Population in a Comprehensive Prepaid Group Practice Program." Medical Care 10 (May-June 1972) : 187-200. 
Greenlick, Merwyn R., Hurtado, Arnold V., Pope, Clyde R., Saward, Ernest $W_{.}$, and Yoshioka, Samuel S. "Determinants of Medical Care Utilization." Health Services Research (Winter 1968):296-315.

Greenlick, Merwyn R. "Medical Services to Poverty Groups." In The Kaiser-Permanente Medical Care Program: a Symposium, pp.138-148. Edited by Anne R. Somers. New York: The Commonwealth Fund, Inc., 1971.

Handschin, Richard. "Utilization of Comprehensive Medical Services by Public Assistance Patients During the First Six Months of Enrollment in a Prepaid Group Practice." Seattle, Washington. 15 January 1971 .

Harrington, Michael. The Other America. New York: Penguin, 1963.

Hurtado, Arnold V., Greenlick, Merwyn R., and Colombo, Theodore J. "Determinants of Medical Care Utilization: Failure to Keep Appointments." Medical Care 11 (MayJune 1973):189-198.

Jaco, E. Gartly, ed. Patients, Physicians, and Illness. New York: The Free Press, 1972 .

Kahn, Alfred J. Social Policy and Social Service. New York: Random House, 1973.

Kegeles, S. Stephen. "Problems of Experimental Research in the Urban Ghetto." Medical Care 7 (September-October 1969) : 395-405.

Kent, James A., and Smith, C. Harvey. "Involving the Urban Poor in Health Services Through Accommodation---the Employment of Neighborhood Representatives." Amer. J. Public Health LVII (June 1967):997-1003.

Koos, Earl L. The Health of Regionville: What the People Thought and Did About It. New York: Hafner Publishing Co., 1954 .

Kosa, John, Antonovsky, Aaron, and Zola, Irving K., eds. Poverty and Health. Cambridge, Mass.: Harvard University Press, 1969. 
Lepper, Mark H., Lashof, Joyce C., Pisani, Albert, and Shannon, Iris. "An Approach to Reconciling the Poor and the System." Inquiry V (March 1968):37-42.

Lerner, Monroe. "The Level of Physical Health of the Poverty Population: a Conceptual Reappraisal of Cultural Factors." Medical Care 6 (September-October 1968) : 355-367.

Levinson, Perry, and Schiller, Jeffry. "Role Analysis of the Indigenous Nonprofessional." Social Work 11 (July 1966) : 95-101.

Luckham, Jane, and Swift, David W. "Community Health Aides in the Ghetto: the Contra Costa Project." Medical Care 7 (July-August 1969):332-339.

Milne, Thomas L. "A Drug Education Program for Community Outreach Workers," J. Amer. Pharmaceutical Association (September 1972):454-456.

Monteiro, Lois A. "Expense is No Object: Income and Physician Visits Reconsidered." J. of Health and Social Behavior 14 (June 1973):99-115.

Moody, Philip M., and Gray, Robert M. "Social Class, Social Integration, and the Use of Preventive Health Services." In Patients, Physicians, and Illness, pp. 250-261. Edited by E. Gartly Jaco. New York: The Free Press, 1972 .

Moore, Frank I., and Stewart, James C., Jr. "Important Variables Influencing Successful Use of Aides." Health Services Reports LXXXVII (June-July 1972): 555-561.

Morris, Naomi, Hatch, Martha H., and Chipman, Sidney S. "Deterrents to Well-Child Supervision." Amer. J. Public Health LVI (August 1966): 1232-1241.

Nolan, Robert L., Schwartz, Jerome L., and Simonian, Kenneth. "Social Class Differences in Utilization of Pediatric Services in a Prepaid Direct Service Medical Care Program." Amer. J. Public Health LVII (January 1967) :34-47 . 
Pfotenhauer, Robert. "The Tacoma Health Delivery System: a Comparative Study. Low and Middle Income Consumers." Report prepared by the Tacoma Area Urban Coalition. Tacoma, Washington. Undated.

Podell, Lawrence. "Studies in the Use of Health Services by Families on Welfare: Utilization of Preventive Health Services (Supplementary Report). New York. Undated.

Pope, Clyde R., Freeborn, Donald K., and Greenlick, Merwyn $R$. "Use of Outside Physicians by Members of a Group Practice Prepayment Plan." Paper presented at the 100th Annual Meeting of the American Public Health Association, Atlantic City, N.J., November 1972 .

Rabin, David L., Bice, Thomas W., and Starfield, Barbara. "Use of Health Services by Baltimore Medicaid Recipients." Medical Care 12 (July 1974):561-570

Rabin, David L., and Schach, Elisabeth. "Medicaid, Morbidity, and Physician Use." Medical Care 13 (July 1975) :68-78.

Ramsey, Paul. The Patient as Person: Explorations in Medical Ethics. New Haven, Conn.: Yale University Press, 1970 .

Rein, Martin. Social Policy: Issues of Choice and Change. New York: Random House, 1970.

Riessman, Catherine Kohler. "The Use of Health Services by the Poor." Social Policy (May-June 1974):41-49.

Rosenblatt, Daniel, and Suchman, Edward A. "Blue-Collar Attitudes and Information Toward Health and Illness." In Blue-Collar World: Studies of the American Worker, pp. 324-333. Edited by Arthur B. Shostak and William Gomberg. Englewood Cliffs, N.J.: PrenticeHall, 1964 .

Rosenblatt, Daniel, and Suchman, Edward A. "The Under-Utilization of Medical Care Services by Blue-Collarites." In Blue-Collar World: Studies of the American Worker, Edited by Arthur B. Shostak and William Gomberg. Englewood Cliffs, N.J.: Prentice-Hall, 1964 . 
Rosenstock, Irwin M. "Prevention of Illness and Maintenance of Health." In Poverty and Health, pp. 193-223. Edited by John Kosa, Aaron Antonovsky, and Irving $K$. Zola. Cambridge, Mass.: Harvard University Press, 1969 .

Sparer, Gerald, and Anderson, Arne. "Utilization and Cost Experience of Low-Income Families in Four Prepaid Group Practice Plans." New Eng1. J. Medicine 289 (July 12, 1973):67-72.

Sparer, Gerald, and Okada, Louise M. "Chronic Conditions and Physician Use Patterns in Ten Urban Poverty Areas." Medical Care 12 (July 1974):549-560.

Stevens, Robert, and Stevens, Rosemary. Welfare Medicine in America: a Case Study of Medicaid. New York: The Free Press, 1974 .

Stoeckle, J.D., and Twaddle, A.C. "Non-Physician Health Workers: Some Problems and Prospects." Social Science and Medicine 8 (February 1974):71-76.

Strauss, Anselm. "Medical Ghettos." In Patients, Physicians, and Illness, pp. 381-388. Edited by E. Gartly Jaco. New York: The Free Press, 1972.

Suchman,Edward A. "Social Factors in Medical Deprivation." Amer. J. Public Health IV (November 1965):1725-1733.

Suchman, Edward A. "Social Patterns of Illness and Medical Care." In Patients, Physicians, and Illness, pp. 262279. Edited by E. Gartly Jaco. New York: The Free Press, 1972 .

Turner, Phyllis. "Review of the Literature Pertaining to the Employment of Indigenous Nonprofessionals in Health Services Programs." Paper prepared for Health Services Research Center-Kaiser Foundation Hospitals. Portland, Oregon, 1975. 
U.S., Department of Health, Education, and Welfare. Health Services and Mental Health Administration. Health Maintenance Organization Service, Public Health Service. Some Information Descriptive of a Successfully Operating Health Maintenance Organization, by Ernest Saward, Janet Blank, and Henry Lamb. Publication No. (HSM) 73-13011. Rockville, Maryland: Government Printing Office, 1973 .

U.S.,Office of Economic Opportunity. Guidelines. The Comprehensive Neighborhood Health Services Program, Health Services Office. Washington, D.C.: Government Printing Office (March 1968).

Weiss, James, Freeborn, Donald K., and Lamb, Sara. "Use of Mental Health Services by Poverty and Nonpoverty Members of a Prepaid Group Practice Plan." Health Services Reports 88 (August-September 1973):653-662.

White, Elijah L. "A Graphic Presentation on Age and Income Differentials in Selected Aspects of Morbidity, Disability, and Utilization of Health Services." Inquiry $V($ March 1968): 18-30.

Wingert, Willis A., Grubbs, Judy, Lenoski, Edward F., and Friedman, David B. "Effectiveness and Efficiency of Indigenous Health Aides in a Pediatric Outpatient Department." Amer. J. Public Health LXV (August 1975): 849-857.

Wingert, Willis A., Larson, William, and Friedman, David B. "Indigenous Health Aides as Counselors to Parents About Nutrition." Public Health Reports LXXXIV (April 1969) : 328-332 .

Wise, Harold, Beckhard, Richard, Rubin, Irwin, and Kyte, Aileen L. Making Health Teams Work. Cambridge, Mass.: Ballinger, 1974 .

Wise, Harold, Torrey, E. Fuller, McDade, Adrienne, Perry, Gloria, and Bograd, Harriet. "The Family Health Worker." Amer. J. Public Health LVIII (October 1968) : 1828-1838. 
TABLE 1. Rate Per Hundred Person/Years of Distribution of Primary Immunizations for Total Health Plan Sample and Neighborhood Health Center Population, 1972.

\begin{tabular}{|c|c|c|c|c|c|c|c|c|c|c|}
\hline \multirow[b]{3}{*}{ MALES } & \multirow[b]{3}{*}{ Age } & \multirow{2}{*}{\multicolumn{3}{|c|}{ Health Plan }} & \multicolumn{6}{|c|}{ Neighborhood Health Center } \\
\hline & & \multirow{2}{*}{\multicolumn{2}{|c|}{ No. Pers/Yrs }} & & \multirow{2}{*}{\multicolumn{3}{|c|}{$\begin{array}{l}\text { With Coordinator } \\
\text { No. Pers/Yrs } \\
\text { Notere } \\
\end{array}$}} & \multirow{2}{*}{\multicolumn{3}{|c|}{$\begin{array}{l}\text { Without Coordinator } \\
\text { No. Pers/Yrs Rate }\end{array}$}} \\
\hline & & & & Rate & & & & & & \\
\hline & $0-4$ & 832 & 426.00 & $195 \cdot 30$ & 509 & 303.83 & 167.52 & 122 & $90 \cdot 50$ & 134.80 \\
\hline & $5-9$ & 221 & 405.00 & 54.56 & 223 & 490.83 & 45.43 & 62 & $149 \cdot 34$ & 41.51 \\
\hline & $10-14$ & 189 & 470.50 & 40.17 & 206 & 494.67 & 41.64 & 45 & 144.75 & 31.08 \\
\hline & $15-19$ & 65 & 390.25 & 16.65 & 42 & $410 \cdot 33$ & 10.23 & 20 & 125.67 & 15.91 \\
\hline & $20+$ & 59 & 2392.07 & 2.47 & 12 & 587.23 & 2.04 & 3 & 140.76 & 2.13 \\
\hline TOTAL & MALES & 1366 & 4083.83 & 33.45 & 992 & 2286.89 & $43 \cdot 37$ & 252 & 651.02 & 38.70 \\
\hline \multicolumn{11}{|c|}{ FEMALES } \\
\hline- & $0-4$ & 742 & 370.33 & $200 \cdot 36$ & 508 & 316.00 & 160.75 & 127 & 95.33 & 133.22 \\
\hline & $5-9$ & 272 & 445.08 & 61.11 & 234 & 493.09 & 47.45 & 65 & 137.75 & 47.18 \\
\hline & $10-14$ & 159 & 455.83 & 34.88 & 230 & 569.75 & 40.36 & 57 & 155.92 & 36.55 \\
\hline & $15-19$ & 42 & 384.92 & 10.91 & 50 & 434.09 & 11.51 & 24 & 130.67 & 18.36 \\
\hline & $20+$ & 124 & 2608.34 & 4.75 & 36 & 1143.17 & 3.14 & 8 & 316.34 & 2.52 \\
\hline TOTAL & FEMALES & 1339 & 4264.50 & 31.39 & 1058 & 2956.10 & 35.79 & 281 & 836.01 & 33.61 \\
\hline $\begin{array}{l}\text { TOTA } \\
\text { AND }\end{array}$ & $\begin{array}{l}\text { MALES } \\
\text { EMALES }\end{array}$ & 2705 & & & 2050 & & & 533 & & \\
\hline
\end{tabular}


TABLE 2. Rate Per Hundred Person/Years of Distribution of Preventive Physical Examinations for Males in Total Health Plan Sample and Neighborhood Health Center Population, 1972 .

\begin{tabular}{|c|c|c|c|c|c|c|c|c|c|c|}
\hline \multirow[b]{3}{*}{ MALES } & \multirow[b]{3}{*}{ Age } & \multicolumn{3}{|c|}{ Health Plan } & \multicolumn{6}{|c|}{ Neighborhood Health Center } \\
\hline & & \multirow[b]{2}{*}{ No. } & \multirow[b]{2}{*}{ Pers/Yrs } & \multirow[b]{2}{*}{ Rate } & \multicolumn{3}{|c|}{ With Coordinator } & \multicolumn{3}{|c|}{ Without Coordinator } \\
\hline & & & & & No. & Pers/Yrs & Rate & No & Pers/Yrs & Rate \\
\hline & $0-4$ & 558 & 426.00 & 130.99 & 285 & 303.83 & 93.80 & 79 & 90.50 & 87.29 \\
\hline & $5-9$ & 160 & 405.00 & 39.51 & 134 & 490.83 & 27.30 & 43 & 149.34 & 28.79 \\
\hline & $10-14$ & 149 & 470.50 & 31.67 & 132 & 494.67 & 26.68 & 37 & 144.75 & 25.56 \\
\hline & $15-19$ & 105 & 390.25 & 26.90 & 72 & 410.33 & 17.55 & 24 & 125.67 & 19.10 \\
\hline & $20-24$ & 62 & 334.50 & 18.53 & 17 & 163.33 & 10.41 & 5 & 43.17 & 11.58 \\
\hline & $25-29$ & 65 & 365.83 & 17.76 & 7 & 69.58 & 10.06 & 2 & 13.00 & 15.38 \\
\hline & $30-34$ & 56 & 300.50 & 18.63 & 10 & 71.59 & 13.97 & 4 & 20.92 & 19.12 \\
\hline & $35-39$ & 57 & 231.25 & 24.65 & 16 & 70.58 & 22.67 & 2 & 16.09 & 12.43 \\
\hline & $40-44$ & 56 & 212.83 & 26.31 & 10 & 65.08 & 15.37 & 2 & 10.41 & 19.21 \\
\hline & $45-49$ & 35 & 193.33 & 18.10 & 13 & $45 \cdot 33$ & 28.68 & 4 & 15.67 & 25.53 \\
\hline & $50-54$ & 60 & 196.33 & 30.56 & 5 & 31.58 & 15.83 & 1 & 4.00 & 25.00 \\
\hline & 55-59 & 55 & 172.58 & 31.87 & 6 & $23 \cdot 58$ & 25.45 & 1 & 9.50 & 10.53 \\
\hline & $60-64$ & 54 & 139.92 & 38.59 & 9 & 23.25 & 38.71 & 1 & 6.00 & 16.67 \\
\hline & $65+$ & 103 & 245.00 & 42.04 & 9 & 23.33 & 38.58 & 0 & 2.00 & 00.00 \\
\hline TOTAL & ILES & 1575 & 4083.83 & 38.57 & 725 & 2286.89 & 31.70 & 205 & 651.02 & 31.49 \\
\hline
\end{tabular}


TABLE 3. Rate Per Hundred Person/Years of Distribution of Preventive Physical Examinations for Females in Total Health Plan Sample and Neighborhood Health Center Population, 1972 .

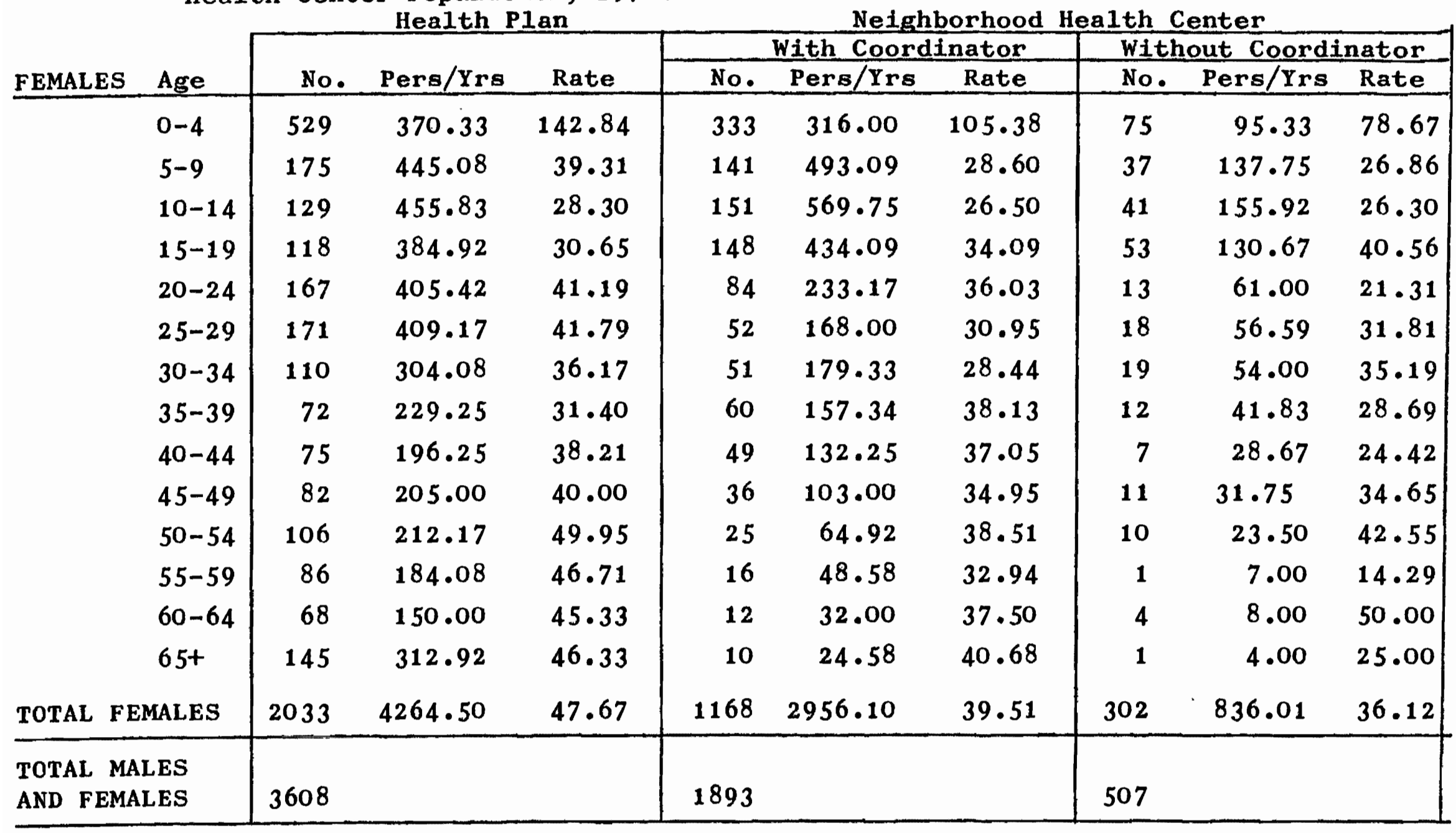


TABLE 4. Rate Per Hundred Person/Years of Distribution of Pap Smears for Total Health Plan Sample and Neighborhood Health Center Population, 1972.

\begin{tabular}{|c|c|c|c|c|c|c|c|c|c|c|}
\hline \multirow[b]{3}{*}{ FEMALES } & \multirow[b]{3}{*}{ Age } & \multirow{2}{*}{\multicolumn{3}{|c|}{ Health Plan }} & \multicolumn{6}{|c|}{ Neighborhood Health Center } \\
\hline & & & & & \multicolumn{3}{|c|}{ With Coordinator } & \multicolumn{3}{|c|}{ Without Coordinator } \\
\hline & & No. & Pers/Yrs & Rate & No. & Pers/Yrs & Rate & No. & Pers/Yrs & Rate \\
\hline & $0-4$ & 0 & 370.33 & 00.00 & 0 & 316.00 & 00.00 & 0 & 95.33 & 00.00 \\
\hline & $5-9$ & 0 & 445.08 & 00.00 & 0 & 493.09 & 00.00 & 0 & 137.75 & 00.00 \\
\hline & $10-14$ & 3 & 455.83 & 00.66 & 12 & 569.75 & 02.11 & 4 & 155.92 & 02.57 \\
\hline & $15-19$ & 101 & 384.92 & 26.24 & 172 & 434.09 & 39.62 & 43 & 130.67 & 32.91 \\
\hline & $20-24$ & 271 & 405.42 & 66.84 & 153 & 233.17 & 65.62 & 35 & 61.00 & 57.38 \\
\hline & $25-29$ & 285 & 409.17 & 69.65 & 87 & 168.00 & 51.79 & 26 & .56 .59 & 45.94 \\
\hline & $30-34$ & 183 & 304.08 & 60.18 & 91 & 179.33 & 50.74 & 24 & 54.00 & 44.44 \\
\hline & $35-39$ & 98 & 229.25 & 42.75 & 56 & $157 \cdot 34$ & $35 \cdot 59$ & 14 & 41.83 & 33.47 \\
\hline & $40-44$ & 103 & 196.25 & 52.48 & 49 & 132.25 & 37.05 & 14 & 28.67 & 48.83 \\
\hline & $45-49$ & 91 & 205.00 & $44 \cdot 39$ & 40 & 103.00 & 38.83 & 20 & 31.75 & 62.99 \\
\hline & $50-54$ & 103 & 212.17 & 48.55 & 19 & 64.92 & 29.27 & 5 & 23.50 & 21.28 \\
\hline & $55-59$ & 72 & 184.08 & 39.11 & 12 & 48.58 & 24.70 & 0 & 7.00 & 00.00 \\
\hline & $60-64$ & 62 & 150.00 & $41 \cdot 34$ & 10 & 32.00 & 31.25 & 4 & 8.00 & 00.50 \\
\hline & $65+$ & 123 & 312.92 & 39.31 & 8 & $24 \cdot 58$ & 32.55 & 1 & 4.00 & 00.25 \\
\hline OTAL FE & MALES & 1495 & 4083.83 & 36.61 & 709 & 2956.10 & 23.98 & 190 & 836.01 & 22.73 \\
\hline
\end{tabular}

